\title{
BIOSYNTHESIS OF ESTERIFIED ALKAN-2-OLS AND $\beta$-DIKETONES IN BARLEY SPIKE EPICUTICULAR WAX: SYNTHESIS OF RADIOACTIVE INTERMEDIATES
}

\author{
by \\ JØRN DALGAARD MIKKELSEN
Department of Physiology, Carlsberg Laboratory, Gamle Carlsberg Vej 10, DK-2500 Copenhagen Valby
and
Institute of Genetics, University of Copenhagen, Øster Farimagsgade 2A, DK-1353 Copenhagen $\mathrm{K}$

Keywords: High performance liquid chromatography, radio-gas chromatography, mass spectrometry, $\beta$-diol trimethylsilyl ethers, $\left(9,10-{ }^{3} \mathrm{H}\right)$-3-oxopalmitoyl-CoA, $\left(1-{ }^{14} \mathrm{C}\right)$-3-oxopalmitoyl-CoA, $\left(9,10-{ }^{3} \mathrm{H}\right)$-L-3-hydroxypalmitoyl-CoA, $\left(2-{ }^{14} \mathrm{C}\right)$-pentadecan-2-one, $\left(10,11-{ }^{3} \mathrm{H}\right)$-heptadecan-2-one, $\left(2-{ }^{3} \mathrm{H}\right)$-pentadecan-2-ol, $\left(3-{ }^{14} \mathrm{C}\right)$-3-oxopalmitic acid methyl ester, $\left(3-{ }^{14} \mathrm{C}\right)-\mathrm{DL}-3-$ hydroxypalmitic acid, $\left(1-{ }^{14} \mathrm{C}\right)-10,12$-dioxoeicosanoic acid, reductase, decarboxylase, ester synthetase, eceriferum.

Thirteen different ${ }^{14} \mathrm{C}$-and ${ }^{3} \mathrm{H}$-labelled epicuticular wax precursors have been synthesized and their structure determined by gas chromatography-mass spectrometry analyses. The biosyntheses of $\beta$-diketones and alkan- 2 -ol containing esters were studied by incorporating these intermediates into tissue slices of barley spikes whose awns had been removed. A differential labelling pattern of the alkan-2-ol esters and the $\beta$-diketones was observed after feeding three selected mutants blocked in different steps catalyzed by a multifunctional enzyme encoded for by the cer-cqu gene. In $c e r-u^{69}$ tissue slices $\left(9,10-{ }^{3} \mathrm{H}\right)-3$-oxopalmitoyl-CoA was incorporated into both the esterified alkan-2-ols and the $\beta$-diketones. Only the former wax component was synthesized by the mutants $c e r-c^{36}$ and $-q^{42}$. When $C_{14}$ and $C_{16}$ fatty acyl chains were fed to the tissue slices, those of $c e r-u^{69}$ and $-c^{36}$ readily labelled the esterified alkan-2-ols, whereas those of $c e r-q^{42}$ were totally inactive. In all three mutants $\left(2-{ }^{14} \mathrm{C}\right)$-pentadecan-2-one, (10,11- $\left.{ }^{3} \mathrm{H}\right)$-heptadecan-2-one and $\left(2-{ }^{3} \mathrm{H}\right)$-pentadecan-2-ol exclusively labelled the alkan-2-ol moieties of the specified esters. $\left(9,10-{ }^{3} \mathrm{H}\right)$-L-3-hydroxypalmitoyl-CoA and $\left(3-{ }^{14} \mathrm{C}\right)$-labelled DL-3-hydroxy fatty acids having 14,16 and 18 carbon atoms were incorporated with a very low efficiency into the $\beta$-diketones and the esterified alkan-2-ols. $\left(9,10-{ }^{3} \mathrm{H}\right.$ )-3-oxopalmitoyl-CoA is the primer for the enzyme system known as $\beta$-ketoacyl elongase which forms the $C_{29}$ (nonacosan-14,16-dione), $C_{31}$ (hentriacontan-14,16-dione) and $C_{33}$ (tritriacontan-16,18-dione) $\beta$-diketones. After protection of the $\beta$-dicarbonyl group, 7 or $8 C_{2}$ units are added before the presumed decarboxylation to yield the complete $\beta$-diketone carbon chain. The alkan-2-ol esters arise from the 3-oxoacyl-CoA derivative by an initial decarboxylation to form a methyl ketone, followed by a reduction to an alkan-2-ol. The latter is then esterified with a fatty acid to form the alkan-2-ol containing esters. The three steps involved in the alkan-2-ol ester synthesis are accomplished by the coordinated action of a decarboxylase, reductase and ester synthetase.

Abbreviations: CoA = coenzyme A, GC = gas chromatography, GC-MS = gas chromatography-mass spectrometry, HPLC $=$ high performance liquid chromatography, TLC $=$ thin layer chromatography, TMS $=$ trimethylsilyl, Tris $=$ tris(hydroxymethyl)-aminomethane. 


\section{INTRODUCTION}

The synthesis and deposition of the epicuticular lipids in barley are controlled by the eceriferum (cer) genes $(38,39,69,70,73,74,75,76$, 77). Compositional analyses of wax on spikes of various cer mutants led to the deduction that the esterified alkan-2-ols, primarily tridecan-2-ol and pentadecan-2-ol (72) are more closely related biosynthetically to the $\beta$-diketones $(96 \%$ hentriacontan-14,16-dione, $C_{31}$ ) than to any other wax class $(73,74,75,76)$. Radioactive tracer and inhibitor studies have shown that the carbon chain of the $C_{31} \beta$-diketone is formed by elongation by an enzyme system termed the $\beta$-ketoacyl elongase $(43,49)$. Investigation of the primer specificity for the $\beta$-ketoacyl elongase showed that a $C_{14}, C_{15}$ or a $C_{16}$ fatty acid could be used to form the $\beta$-diketones. $C_{12}$ chains were first elongated before incorporation and $\mathrm{C}_{18}$ chains were inactive (43). Similar results have been obtained for the alkan-2-ol containing esters using $C_{12}, C_{14}, C_{16}$ and $C_{18}$ fatty acids as precursors $(44,76)$. Cyanide inhibits the synthesis of both the $\beta$-diketones and the alkan-2-ol containing esters to a similar extent $(44,76)$.

Three different complementing groups of mutations, $c e r-c$, $-q$ and $-u$ interfere with the synthesis of the $\beta$-ketoacyl derived lipids but have no effect on the other epicuticular lipids (75). The mutation $c e r-u^{69}$ results in an inhibition of the hydroxy- $\beta$-diketone synthesis which is accompanied by increased compensatory amounts of the $\beta$-diketones. In $c e r-c^{36}$ plants the formation of the $\beta$-diketones and hydroxy- $\beta$-diketones is blocked and enhanced amounts of the esterified alkan-2-ols are synthesized. No $\beta$ ketoacyl derived lipids are present in cer- $q^{42}$. The results of genetic analyses imply that cer-cqu is a gene encoding for a single polypeptide having several catalytic domains $(75,76)$. To elicit further, the roles of cer-cqu and the $\beta$-ketoacyl elongase in synthesis of $\beta$-diketone lipids and esterified alkan-2-ols, the biosynthetic steps involved must be identified and ultimately the enzymes must be purified. The present studies describe the synthesis of suspected intermediates involved in these pathways. The results obtained by feeding them to tissue slices have led to the identification of i) the enzymatic reactions in the esterified alkan-2-ol pathway, ii) the identity of the $\beta$-ketoacyl elongase primer and iii) the enzymatic reaction determined by the wild type allele of cer-q.

\section{MATERIALS AND METHODS}

\subsection{General}

Location of radioactive lipids on the thin layer plates, purification of individual lipid classes by preparative TLC and determination of radioactivity among the lipid classes are detailed elsewhere $(3,41,42,43)$. The amounts of label in the lipid classes separated by TLC are expressed as the average of three independent experiments. The distributions of label among the various chain lengths have been calculated from at least two injections into the radio-gas chromatograph. Gas chromatography-mass spectrometry (GC-MS) was carried out as described previously (43).

\subsection{Plant materials}

Seeds of the barley eceriferum mutants cer- $u^{69}$, $-c^{36}$, and $-q^{42}(36,37)$ were grown in a Weiss Model $20 \mathrm{RB} / 5$-JU-P growth chamber in continuous light, the 24,000 lumen supplied by Osram HQI-E, $400 \mathrm{~W} / \mathrm{D}$ lamps. The thermoperiod was 16 hours at $17^{\circ} \mathrm{C}$ and 8 hours at $12^{\circ} \mathrm{C}$.

\subsection{Chemicals}

Sodium boro- $\left({ }^{3} \mathrm{H}\right)$-hydride $(348 \mathrm{mCix}$ $\left.\mathrm{mmol}^{-1}\right),\left(1-{ }^{14} \mathrm{C}\right)$-lauric acid $\left(32 \mathrm{mCixmmol}^{-1}\right)$, $\left(1-{ }^{14} \mathrm{C}\right)$-palmitic acid $\left(56 \mathrm{mCi} \times \mathrm{mmol}^{-1}\right),(9,10$ -

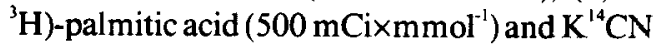
$\left(58 \mathrm{mCi} \times \mathrm{mmol}^{-1}\right)$ were purchased from New England Nuclear (Boston, Mass. USA). (1- $\left.{ }^{14} \mathrm{C}\right)$ myristic acid $\left(45 \mathrm{mCi} \times \mathrm{mmol}^{-1}\right)$ was obtained from Rosechem Products (North Hollywood, Cal., USA). Coenzyme A (CoA), NAD ${ }^{+}$, L-lactate: $\mathrm{NAD}^{+}$oxidoreductase (EC 1.1.1.27), L-3hydroxyacyl-CoA:NAD ${ }^{+}$oxidoreductase (EC 1.1.1.35), acyl-CoA oxidase and pyruvate were from Sigma Chemical Company (St. Louis, Mo., U.S.A.). 2,2-dimethyl-1,3-dioxane-4,6dione (Meldrum's acid) was a product of RiedelDe Häen AG (Hannover, West Germany). Dichloromethane, triethylamine, tris(hydroxymethyl)-aminomethane (Tris) and acetonitrile 
(HPLC grade) were from Merck (Darmstadt, W. Germany). Pyridine, trimethylchlorosilane, trimethylsilylimidazole and N,N-bis-trimethylsilyltrifluoroacetamide were purchased from Macherey-Nagel (Düren, West Germany). Ethylchloroformate and 5,5'-dithio-bis(2-nitrobenzoic acid) were from Ferak (Berlin, W. Germany) and Fluka AG (Buchs, Switzerland), respectively. Palladium on calcium carbonate poisoned with lead (5\% Pd, Lindlar's catalyst) was from Janssen Chimica (Beerse, Belgium). Methoxyamine hydrochloride was purchased from Serva (Heidelberg, W. Germany). Trans-2hexadecenoic acid came from ICN Pharmaceuticals Inc. Life Science Group (Plainview, N.Y., USA). Pentadecan-2-one and 3-hydroxymyristic acid methyl ester were purchased from Analabs (North Haven, Conn., U.S.A.). Pure sterculic acid (19) was a gift from Dr. A. FoGERTY, CSIRO Division of Food Research, Australia. Seeds of Sterculia foetida were a gift from Dr. R.E. PAULL, University of Hawaii at Manoa. Enoyl-CoA hydratase (L-3-hydroxyacyl-CoA Hydrolyase, EC 4.2.1.17) was purified from ox liver by the method of STEINMANN and HILL (62).

\subsection{Preparation of substrates}

2.4.1. Chemical synthesis of ${ }^{14} \mathrm{C}$ - and

${ }^{3} \mathrm{H}$-labelled methyl ketones and DL-3hydroxy fatty acids

Methyl ketones and DL-3-hydroxy fatty acids were synthesized from $\left(1-{ }^{14} \mathrm{C}\right)$-labelled myristic and palmitic acids or from $\left(9,10-{ }^{3} \mathrm{H}\right)$-palmitic acid by the procedure outlined in Figure 1 for myristic acid. The fatty acid ( $50 \mu$ moles, 10

Figure 1. Diagram of the chemical synthesis of labelled $\mathrm{C}_{16}$ substrates from $\left(1-{ }^{14} \mathrm{C}\right)$-myristic acid. $\mathrm{I}=$ mixed anhydride of $\left(1-{ }^{14} \mathrm{C}\right)$-myristic acid and ethylformate (from ethylchloroformate), II = Meldrum's acid, III = myristoyl-Meldrum's acid adduct, IV $=\left(3-{ }^{14} \mathrm{C}\right)-3$-oxopalmitic acid methyl ester, $\mathrm{V}=\left(2-{ }^{14} \mathrm{C}\right)$-pentadecan-2one, $\mathrm{VI}=\left(3-{ }^{14} \mathrm{C}\right)$-DL-3-hydroxypalmitic acid methyl ester and VII $=\left(3-{ }^{14} \mathrm{C}\right)$-DL-3-hydroxypalmitic acid. ${ }^{*}=$ starting with labelled $C_{14}$ fatty acid. The same series of reactions were used to synthesize labelled $C_{18}$ substrates.

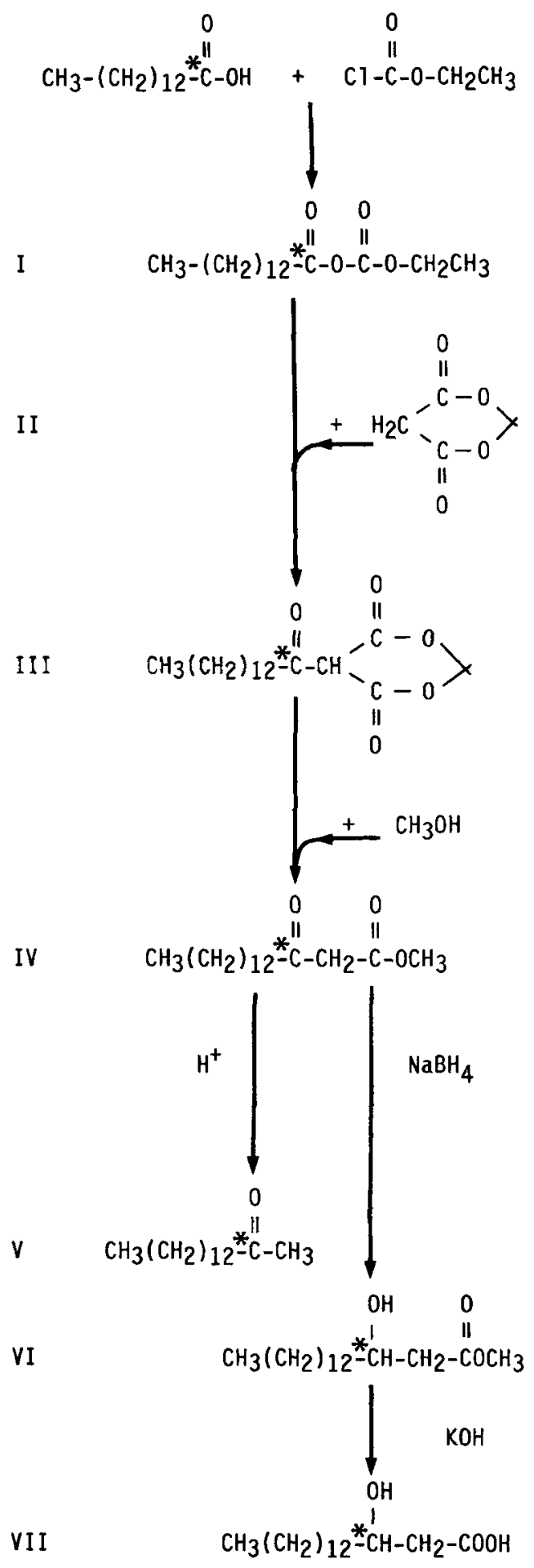




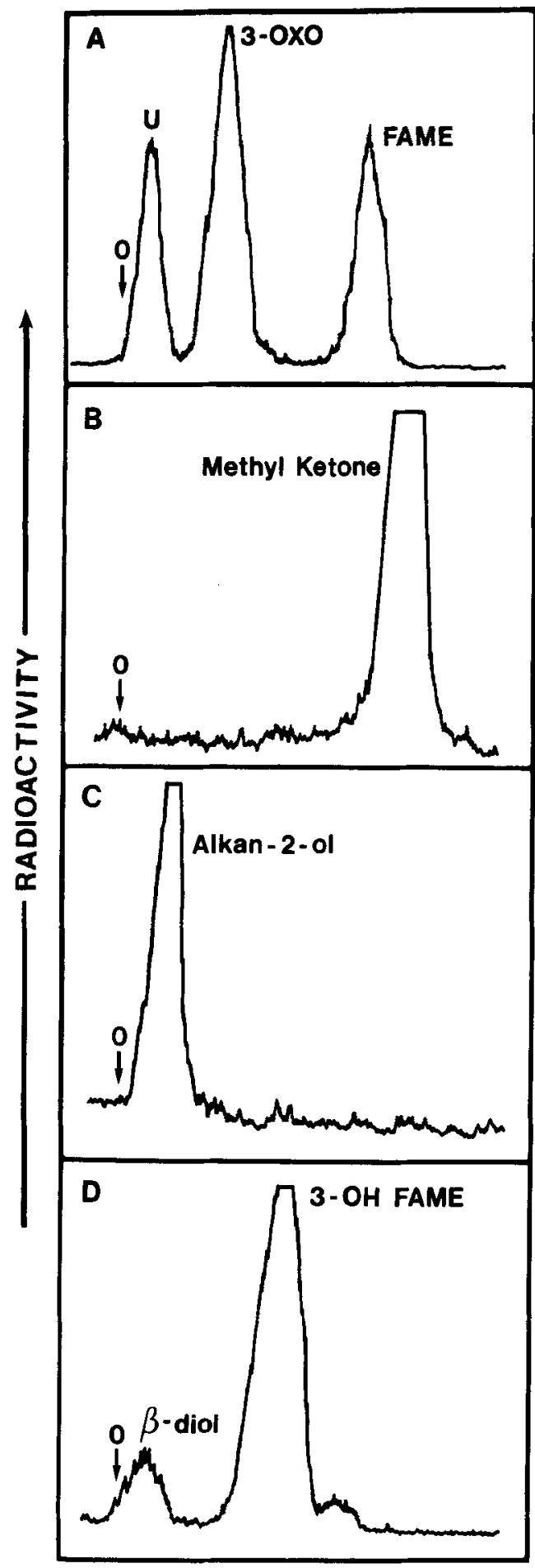

Figure 2. Radio-thin layer chromatograms of lipids produced during the chemical syntheses diagrammed in Figure 1. A: Reaction products formed after methanolysis of myristoyl-Meldrum's acid adduct (III), $\mathrm{U}=$ unknown, 3-oxo $=\left(3-{ }^{14} \mathrm{C}\right)$-3-oxopalmitic acid methyl ester (IV), FAME = fatty acid methyl ester. B: Decarboxylation of IV gives $100 \%\left(2-{ }^{14} \mathrm{C}\right)$-pentadecan-2-one (V). $\mathrm{C}: \mathrm{NaBH}_{4}$ treatment of $\mathrm{V}$ gives $100 \%\left(2-{ }^{14} \mathrm{C}\right)$-pentadecan-2-ol. D: Reaction product formed after $\mathrm{NaBH}_{4}$ treatment of IV, $\beta$-diol $=\left(3-{ }^{14} \mathrm{C}\right)$-hexadecan-1,3-diol and 3-OH-FAME $=\left(3-{ }^{14} \mathrm{C}\right)$-DL-3-hydroxypalmitic acid methyl ester. $\mathrm{CHCl}_{3}$ (stabilized with amylene) was employed as developing solvent in A, B and C. $\mathrm{CHCl}_{3}$ :methanol $(1: 1, \mathrm{v} / \mathrm{v})$ was used in $\mathrm{D} . \mathrm{O}=$ origin.

mCixmmol ${ }^{-1}$ ) was converted into the mixed anhydride of ethylformate (I) by reaction with 1.2 molar excess of both triethylamine and ethylchloroformate as described by SANCHEZ et al. (59). The reaction was carried out in an atmosphere of dry argon. After removal of the solvent and excess reagents by a gentle stream of dry argon, $1 \mathrm{ml} \mathrm{CH}_{2} \mathrm{Cl}_{2}$ containing $90 \mu$ moles of Meldrum's acid (II) and $90 \mu$ moles triethylamine was added dropwise at $0{ }^{\circ} \mathrm{C}$. The reaction vessel was flushed with argon and incubated at $60{ }^{\circ} \mathrm{C}$ for 16 hours. The acyl-Meldrum's acid adduct (III) was isolated and methanolyzed as detailed by OIKAWA et al. (52). (1- $\left.{ }^{14} \mathrm{C}\right)$-3-oxopalmitic acid methyl ester (IV) was synthesized in $40 \%$ yield (of starting label) and purified by TLC using $\mathrm{CHCl}_{3}$ (stabilized with amylene, 43 ) as the developing solvent (see Figure $2 \mathrm{~A}$ ). Compounds containing the 3-oxoacyl ester group were visualized on the TLC plate by spraying with dinitrophenylhydrazine (68). Aliquots of the $\left(3-{ }^{14} \mathrm{C}\right)-3$ oxopalmitic acid methyl ester were treated with a $1 \mathrm{ml}$ solution of acetic acid:concentrated $\mathrm{HCl}$ :water $(5: 3: 2, \mathrm{v} / \mathrm{v})$ and incubated at $40^{\circ} \mathrm{C}$ for 15 hours (45). The incubation mixture was extracted with $5 \times 3 \mathrm{ml} \mathrm{n}$-hexane. Radio-thin layer chromatography (radio-TLC) analysis showed a quantitative conversion of IV into $\left(2-{ }^{14} \mathrm{C}\right)$-pentadecan-2-one $(\mathrm{V})$ (Figures 1 and 2 B). For identification purposes small amounts of $V$ were reduced with $\mathrm{NaBH}_{4}$ to form $\left(2-{ }^{14} \mathrm{C}\right)$ pentadecan-2-ol (Figure $2 \mathrm{C}$ ). Another aliquot of IV was treated with a 5-fold excess of $\mathrm{NaBH}_{4}$ in ethanol at $40{ }^{\circ} \mathrm{C}$ for 3 hours. The resulting (3- $\left.{ }^{14} \mathrm{C}\right)$-DL-3-hydroxypalmitic acid methyl ester 
(VI) was saponified with $4 \% \mathrm{KOH}$ in ethanol:water $(9: 1, v / v, 35)$ to yield $\left(3-{ }^{14} \mathrm{C}\right)$-DL-3-hydroxypalmitic acid (VII, Figure 1). Purification of the hydroxy fatty acid from small amounts of hexadecan-1,3-diol was performed by TLC using $\mathrm{CHCl}_{3}$ :methanol $(1: 1, \mathrm{v} / \mathrm{v})$ as the developing solvent (Figure $2 \mathrm{D})$. The $\left(3-{ }^{14} \mathrm{C}\right)$-DL-3-hydroxy fatty acids with 14,16 and 18 carbon atoms in the chain were synthesized with specific activities of 5,10 and $10 \mathrm{mCi} \times \mathrm{mmol}^{-1}$, respectively. The value for both $\left(2 \cdot{ }^{14} \mathrm{C}\right)$-pentadecan-2-one and $\left(10,11-{ }^{3} \mathrm{H}\right)$-heptadecan-2-one was 10 $\mathrm{mCi} \times \mathrm{mmol}^{-1}$. The specific activities for the latter two substrates were confirmed by radio-gas chromatography (radio-GC) analysis (50).

\subsubsection{Chemical synthesis of $\left(2-{ }^{3} H\right)$-pentadecan- 2-ol}

Eighty $\mu$ moles of pentadecan-2-one were dissolved in $1 \mathrm{ml}$ redistilled ethanol and added dropwise to $72 \mu$ moles $\mathrm{NaB}\left({ }^{3} \mathrm{H}\right)_{4}$. The reaction was allowed to proceed for 3 hours at $25^{\circ} \mathrm{C}$ before $150 \mu$ moles unlabelled $\mathrm{NaBH}_{4}$ was added in order to reduce excess pentadecan-2-one. After 2 more hours unreacted $\mathrm{NaBH}_{4}$ was destroyed with $1 \mathrm{~N}-\mathrm{HCl}$, and $\left(2-{ }^{3} \mathrm{H}\right)$-pentadecan-2ol was recovered by extraction with $5 \times 5 \mathrm{ml}$ $\mathrm{n}$-hexane. The final specific activity was 25.2 $\mathrm{mCi} \times \mathrm{mmol}^{-1}$ according to radio-GC analysis.

\subsubsection{Chemical synthesis of $\left(1-{ }^{14} \mathrm{C}\right)-10,12$ dioxoeicosanoic acid}

Methyl sterculate (I) was converted to $\left(1-{ }^{14} \mathrm{C}\right)$ 10,12-dioxoeicosanoic acid (VI) by chain elongation $(5,6)$ and reductive ozonolysis as shown in Figure 3. Firstly, methyl sterculate was reduced to the corresponding alcohol (II) with 8-fold molar excess of $\mathrm{LiAlH}_{4}(20)$. The reaction product was recovered and purified by column chromatography on Florisil (30) (100-200 mesh Koch-Light Laboratories Ltd. Colnbrook, England) as detailed by FOGERTY et al. (20). The cyclopropene alcohol (II) was converted to the methane sulphonate (III) before treatment with $\mathrm{K}^{14} \mathrm{CN}$. To prevent loss of the cyclopropene ring, the nitrile derivative (IV) was hydrolyzed to form the $C_{20}$ cyclopropene fatty acid (V) by the alkaline method of GENSLER et al. (21). After
I

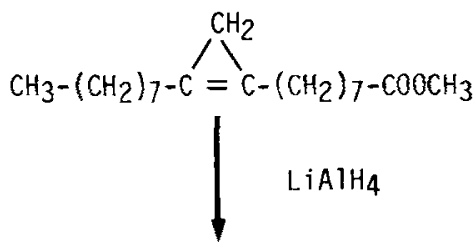

I I

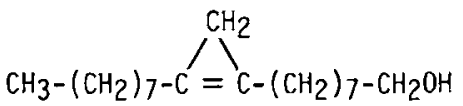

I I I

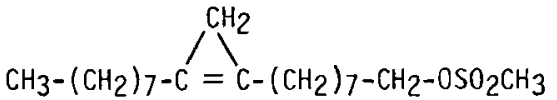

IV

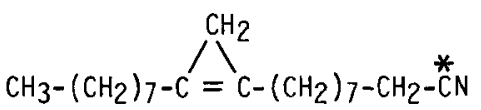

v

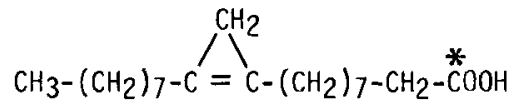

VI

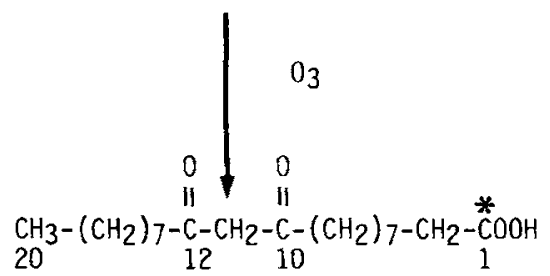

Figure 3. Diagram of the chemical synthesis of $\left(1{ }^{14} \mathrm{C}\right)$ 10.12-dioxoeicosanoic acid. $\mathbf{I}=$ methyl ester of sterculic acid (9,10-methyleneoctadec-9-enoic acid), II, III and IV = the alkan-1-ol, methane sulfonate and nitrile derivatives of sterculic acid, respectively. $\mathrm{V}=10,11$ methylenenonadec-10-enoic acid. $\mathrm{VI}=\left(1-{ }^{14} \mathrm{C}\right)-10,12-$ dioxoeicosanoic acid. ${ }^{*}=$ starting with $\mathrm{K}^{14} \mathrm{CN}$.

acidifying, the liberated fatty acid (V) was recovered by extraction with hexane:diethyl ether $(1: 1, v / v, 21)$. The solvent was evaporated with a gentle stream of nitrogen. The fatty acid was promptly dissolved in ethyl acetate and treated with ozone at $-30^{\circ} \mathrm{C}$ for $5 \mathrm{~min}$ (24). Ten $\mathrm{mg}$ of Lindlar's catalyst was added, and the solution was hydrogenated overnight at $0^{\circ} \mathrm{C}$. The catalyst was filtered off and the solution was reduced to 
dryness under a gentle stream of nitrogen. Purification of the final product $\left(1-{ }^{14} \mathrm{C}\right)-10,12$-dioxoeicosanoic acid (VI) was performed by precipitation with copper acetate in ethanol: petroleum ether $(1: 9, \mathrm{v} / \mathrm{v})$ as detailed $(25)$, followed by preparative TLC using silica gel $H$ type 60 and hexane:diethyl ether:formic acid (50:50:2, v/v) as the developing solvent. Components containing the $\beta$-diketo group were visualized on the thin layer plate by the production of a red color when they were sprayed with a saturated solution of $\mathrm{FeCl}_{3}$ in $\mathrm{CHCl}_{3}(24)$. The final yield of pure $\left(1-{ }^{14} \mathrm{C}\right)$-10,12-dioxoeicosanoic acid was $51 \%$ based on the radioactivity in KCN. For further analyses by radio-GC and GC-MS, (1$\left.{ }^{14} \mathrm{C}\right)$-10,12-dioxoeicosanoic acid was methylated with $\mathrm{BF}_{3}$ in methanol and injected directly or after additional derivations: i) reduction with $\mathrm{NaBH}_{4}$ (43) followed by silylation (see section 2.6) and ii) treatment with methoxyamine in pyridine (26) to form the $\beta$-diol TMS and dimethoxim derivatives, respectively. Further structural identification was achieved using the same strategy previously developed for $\beta$-diketones (43). The $C_{20} \beta$-diketo fatty acid was cleaved on either side of the central carbon atom of the $\beta$-dicarbonyl group (carbon-11, in structure VI, Figure 3) using the iodoform reaction (49). After methylation the reaction products were analysed by radio-TLC and radio-GC plus GC-MS.

To aid in the identification of the $\beta$-diketo fatty acid, oil from Sterculia foetida seeds was extracted with petroleum ether (bp $40-60^{\circ} \mathrm{C}$ ), and transmethylated in methanol containing $1 \%$ sodium methoxide as described by RAJU and REISER (56). Purification was performed by Florisil column chromatography. The fatty acid methyl ester fraction was eluted from the column with $5 \%$ diethyl ether in hexane (20). Reductive ozonolysis was carried out as described above. The resulting products were loaded on another Florisil column $(2 \times 20 \mathrm{~cm})$ and eluted with the stepwise gradient described by FOGERTY et al. (20). The $\beta$-diketo fatty acid methyl ester was eluted with $20 \%$ diethyl ether in hexane. Further purification by copper acetate precipitation followed by preparative TLC (see above) was nescessary to obtain a pure fraction of $\beta$-diketo fatty acid methyl esters (approx. 9\%

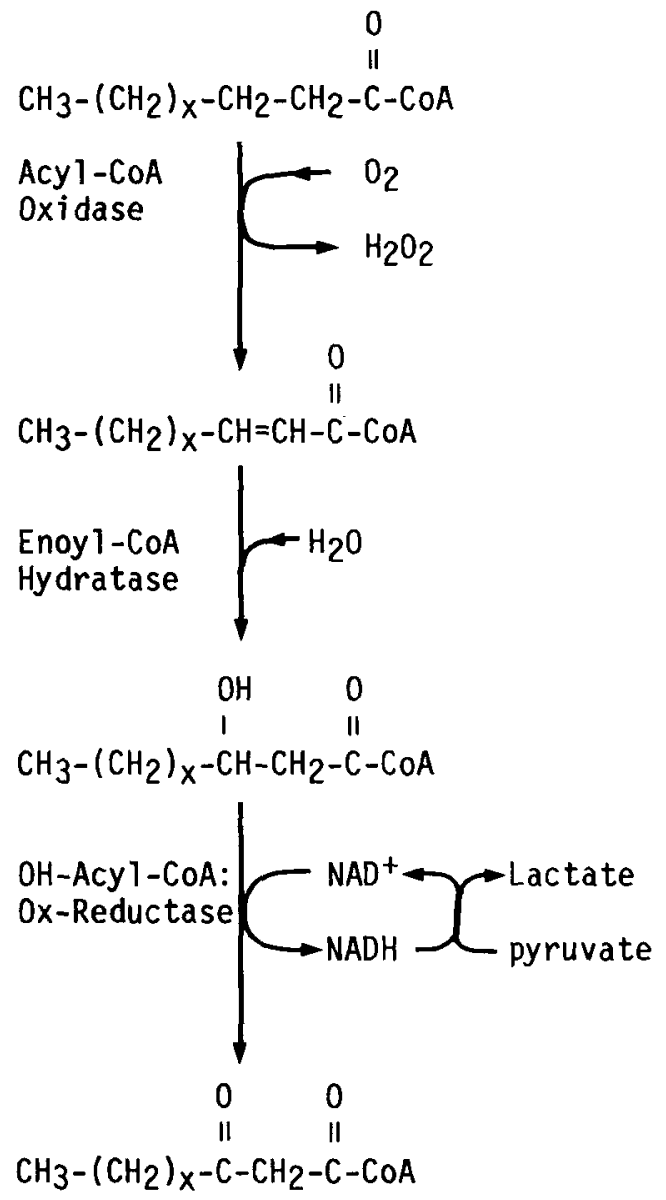

Figure 4. Reaction sequence for the biosynthesis of 3-oxopalmitoyl-CoA catalyzed by the first three enzymes of the $\beta$-oxidation pathway. The starting palmitoyl-CoA was either $\left(9,10-{ }^{3} \mathrm{H}\right)$ - or $\left(1-{ }^{14} \mathrm{C}\right)$-labelled. $\mathrm{X}=$ 12

8,10-dioxooctadecanoic and 91\% 9,11-dioxononadecanoic acids).

\subsubsection{Chemical synthesis of acyl-CoA derivatives}

Fatty acids were converted into acyl-CoA derivatives via their mixed anhydride as described by SANCHEZ et al. (59). The final concentrations were determined either by measuring the absorbance at 236 and $260 \mathrm{~nm}$ (16) or by measuring free and esterified thiol groups using 


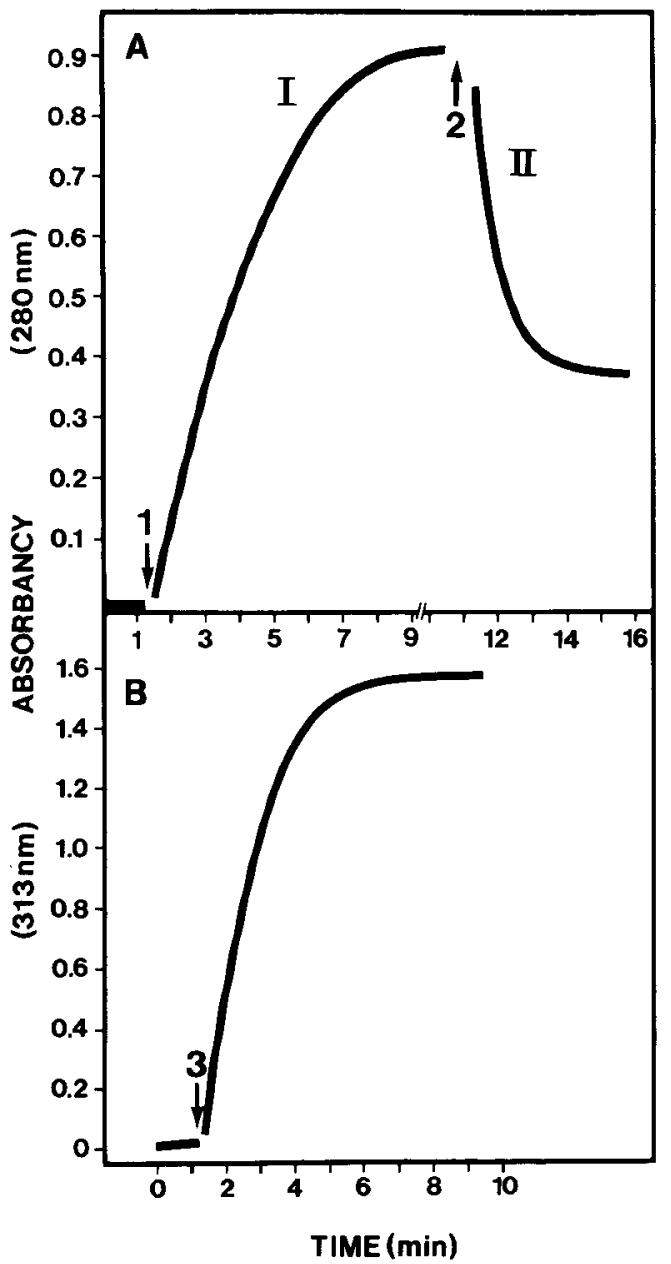

Figure 5. Spectrophotometric detection of the various palmitoyl-CoA derivatives formed by the sequential action of acyl-COA oxidase, enoyl-CoA hydratase and L-3-hydroxyacyl-CoA:NAD ${ }^{+}$oxidoreductase. A: curve I: Production of enoyl-CoA from acyl-CoA in the presence of the first enzyme. curve II: Hydroxylation of enoyl-CoA by the second enzyme. B: Synthesis of 3-oxoacyl-CoA from L-3-hydroxyacyl-CoA catalyzed by the third enzyme. The reaction conditions are detailed in section 2.4.5. Enzymes were added at the time indicated by arrows 1,2 and 3, respectively.

5,5'-dithio-bis(2-nitrobenzoic acid) (18). The specific activities of $\left(1-{ }^{14} \mathrm{C}\right)$-myristoyl-CoA, (1$\left.{ }^{14} \mathrm{C}\right)$-palmitoyl-CoA and $\left(9,10-{ }^{3} \mathrm{H}\right)$-palmitoyl$\mathrm{CoA}$ were $6.9,6.7$ and $61.2 \mathrm{mCixmmol}^{-1}$, respectively.

\subsubsection{Biosynthesis of ${ }^{3} \mathrm{H}$-and ${ }^{14} \mathrm{C}$-labelled L-3-hydroxypalmitoyl-CoA and 3-oxopalmitoy $\mathrm{CoA}$}

Labelled palmitoyl-CoA (see section 2.4.4) was converted in a coupled enzymatic reaction into either L-3-hydroxypalmitoyl-CoA or 3-oxopalmitoyl-CoA with the aid of the first two and three enzymes, respectively, of the $\beta$-oxidation pathway (Figure 4). The enzymes acyl-CoA oxidase, enoyl-CoA hydratase and L-3-hydroxyacyl-CoA:NAD ${ }^{+}$oxidoreductase have different $\mathrm{pH}$ optima $(53,54)$ and a stepwise procedure was therefore adapted. One $\mu$ mole of $\left(1-{ }^{14} \mathrm{C}\right)$-palmitoyl-CoA, dissolved in $400 \mu \mathrm{l}$ water and adjusted to $\mathrm{pH} 5.5$, was transferred to a $3 \mathrm{ml}$ cuvette and diluted with $1.5 \mathrm{ml} 0.1 \mathrm{M}$-Tris at $\mathrm{pH}$ 8.5. The $\mathrm{pH}$ was adjusted to 8.4 with addition of a few drops of $0.4 \mathrm{M}-\mathrm{KHCO}_{3}$. After addition of acyl-CoA oxidase $(0.15$ units, $30 \mu \mathrm{g})$ to the sample but not to the blank, the increase in absorbance against the blank at $280 \mathrm{~nm}$ was followed by an Aminco-Chance Model DW-2A dual wavelength recording spectrophotometer (Figure $5 \mathrm{~A}$ ). When a stable plateau was obtained after approx. $10 \mathrm{~min}, 500 \mu \mathrm{l} 0.2 \mathrm{M}$-Tris containing $0.1 \mathrm{M}-\mathrm{NaCl}$ at $\mathrm{pH} 10.2$ was added to give a final $\mathrm{pH}$ of 8.9. An instantaneous drop in absorbance at $280 \mathrm{~nm}$ was observed when $30 \mu \mathrm{g}$ of enoyl-CoA hydratase was added, and another stable plateau was observed after $6 \mathrm{~min}$ (Figure $5 \mathrm{~A}$ ). To the cuvette was then added $100 \mu \mathrm{l} 0.1$ $\mathrm{M}$-Tris containing $0.1 \mathrm{M}-\mathrm{MgSO}_{4}$ at $\mathrm{pH} 9.8$. The $\mathrm{pH}$ was carefully adjusted to 9.8 with dropwise addition of $1 \mathrm{~N}-\mathrm{NaOH}$. To force the equilibrium of the third enzymatic reaction in the forward direction (60), an $\mathrm{NAD}^{+}$regenerating system consisting of pyruvate (300 $\mu$ moles), L-lactate: NAD ${ }^{+}$oxidoreductase (10 units, $32 \mu \mathrm{g}$ ) and $\mathrm{NAD}^{+}(150 \mu$ moles) was included (Figure 4). The last reaction was initiated by addition of 19 units $(133 \mu \mathrm{g})$ of 3-hydroxyacyl-CoA:NAD ${ }^{+}$oxidoreductase. The increase in absorbance at 313 $\mathrm{nm}$ was followed for $8 \mathrm{~min}$ before a third plateau was obtained (Figure $5 \mathrm{~B}$ ). When the enzymatic reaction was terminated, the acyl-CoA's were precipitated by adjusting the $\mathrm{pH}$ to 1.0 with 6 $\mathrm{N}-\mathrm{HCl}$. Unlabelled palmitoyl-CoA ( $2 \mu$ moles $)$ was added to improve the precipitation. The reaction mixture was kept at $0{ }^{\circ} \mathrm{C}$ for $5 \mathrm{~min}$ before the acyl-CoA's were collected by centrifu- 
gation at $4,000 \times \mathrm{g}$ for $10 \mathrm{~min}$. The pellet was. resuspended in $1.0 \mathrm{ml}$ of $0.1 \mathrm{M}$-Tris $\mathrm{pH}$ at 8.4 and the pH adjusted to 5.5 with $0.4 \mathrm{M}-\mathrm{KHCO}_{3}$. To remove salt and most of the enzymes before the final purification by preparative high performance liquid chromatography (HPLC), the acyl-CoA's were re-precipitated with $6 \mathrm{~N}-\mathrm{HCL}$. This washing procedure was repeated twice. Analysis showed that only $2-4 \%$ of the total radioactivity was lost in this work-up procedure. The final pellet was suspended in $300 \mu \mathrm{l}$ of 16.9 mM-sodium phosphate:acetonitrile $(9 / 1, \mathrm{v} / \mathrm{v})$ buffer at $\mathrm{pH} 6.9$, and the $\mathrm{pH}$ adjusted to 6.0 with $0.4 \mathrm{M}-\mathrm{KHCO}_{3}$. Separation of palmitoyl-CoA, tr-2-hexadecenoyl-CoA, L-3-hydroxypalmitoyl$\mathrm{CoA}$ and 3-oxopalmitoyl-CoA was carried out by preparative HPLC as detailed in section 2.5.

L-3-hydroxypalmitoyl-CoA was synthesized in an analogous way to the 3-oxo homologue except that only acyl-CoA oxidase and enoylCoA hydratase were employed.

\subsection{HPLC}

Analyses were performed using the Waters Assoc. (Milford, Mass., USA) instrument (23). Both analytical and preparative separations were carried out by the use of a prepacked $\mu$ Bondapack C-8 (10 $\mu \mathrm{m}$ particle size) "Radial Pack Cartridge" ( $10 \mathrm{~cm} \times 0.8 \mathrm{~cm}$ i.d.) equipped with an RC SS Guard-Pack C-18 (37-50 $\mu \mathrm{m}$ particle size) pre-column $(0.8 \times 0.5 \mathrm{~cm}$ i.d. $)$. Both column and pre-column were fitted into a Radial Compression Module RCM-100. Elution of the acyl-CoA derivatives was carried out using two buffers, $\mathrm{A}$ and $\mathrm{B}$, containing acetonitrile and 16.9 mM-sodium phosphate at $\mathrm{pH} 6.9$ in premixed volume ratios of $1: 9$ and $7: 3$, respectively. The initial conditions for the multistep gradient were $100 \%$ buffer $A$. The proportion of buffer B was then increased linearly to $30 \%$ during the first $5 \mathrm{~min}$ and over the next 25 $\min$ to $58 \%$. During a subsequent $3 \mathrm{~min}$ period the proportion of buffer B was increased to $100 \%$ where it was maintained for $3 \mathrm{~min}$. The chromatography was carried out at $25^{\circ} \mathrm{C}$ and the flow rate was $1 \mathrm{ml} \mathrm{min}^{-1}$. Elution of the acyl-CoA derivatives was monitored spectrophotometrically at $280 \mathrm{~nm}$ (Figure 6). Analyses of the appropriate HPLC fractions revealed that the

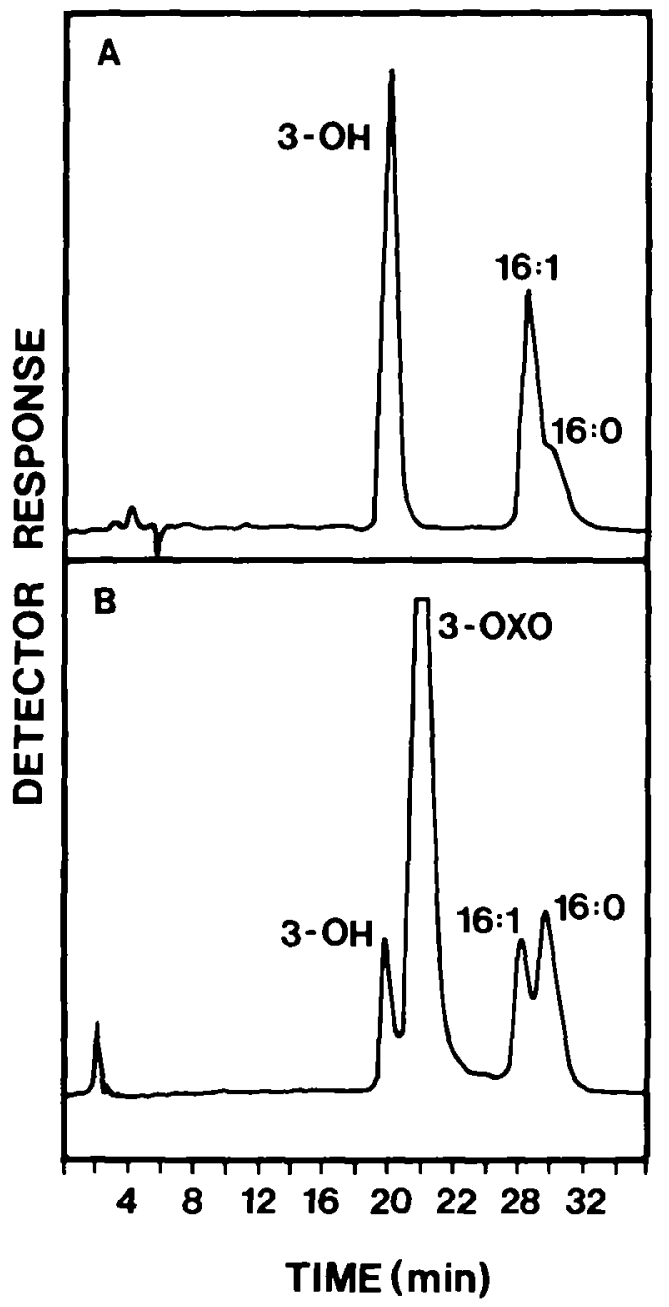

Figure 6. High performance liquid chromatograms of the acyl-CoA derivatives obtained by sequential use of the first two ( $A$ ) or three (B) enzymes of the $\beta$-oxidation pathway illustrated in Figure 4. The CoA derivatives are: 16:0 - palmitate, 16:1 =trans-2-hexadecenoate, 3-OH $=$ L-3-hydroxypalmitate and 3-oxo = 3-oxopalmitate. Separation was carried out using an acetonitrile/phosphate buffer as detailed in section 2.5 . The detector sensitivity was 0.4 absorbance units equal full scale.

$\left(1-{ }^{14} \mathrm{C}\right)-\mathrm{L}-3$-hydroxypalmitoyl-CoA and $\left(1-{ }^{14} \mathrm{C}\right)-$ 3-oxopalmitoyl-CoA comprised 55 and $72 \%$ of the total radioactivity in the samples shown in Figure $6 \mathrm{~A}$ and $\mathrm{B}$, respectively. Conclusive identification of the four acyl-CoA peaks was obtained as follows: Palmitoyl-CoA and trans-2- 


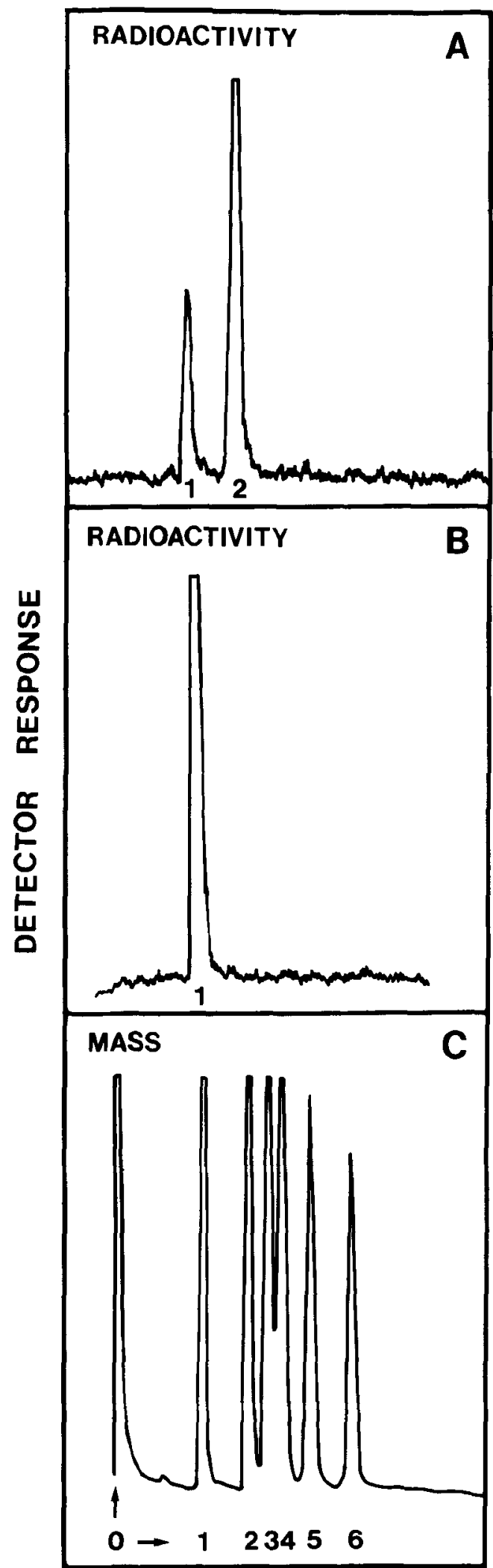

Figure 7. Radio-gas chromatograms of the labelled fatty acid methyl esters isolated from the reaction mixture containing $\left(1{ }^{14} \mathrm{C}\right)$-palmitoyl-CoA and acyl$\mathrm{CoA}$ oxidase. $\mathrm{A}$, before and $\mathrm{B}$, after catalytic hydrogenation (2). $C=$ separation by $G C$ of $I=$ palmitate $\left(C_{16: 0}\right)$, $2=$ trans-2-hexadecenoate $\left(C_{16: 1}\right), 3=$ stearate $\left(C_{18: 0}\right), 4$ $=$ oleate $\left(C_{18: 1}\right), 5=$ linoleate $\left(C_{18: 2}\right)$ and $6=$ linolenate $\left(\mathrm{C}_{18: 3}\right) . \mathrm{O}=$ origin.

hexadecenoyl-CoA co-chromatographed with authentic standards in this HPLC analysis. When $\left(1-{ }^{14} \mathrm{C}\right)$-palmitoyl-CoA was incubated with acyl-CoA oxidase and the reaction products hydrolyzed, the results shown in Figure 7A were obtained. Hydrogenation (2) of the latter converted an unsaturated fatty acid, which co-migrated with trans-2-hexadecenoic acid by radioTLC and -GC, into palmitate (Figure 7 B). The major product from $\left(1-^{14}\right)$-palmitoyl-CoA after the sequential actions of acyl-CoA oxidase, enoyl-CoA hydratase (Figure $6 \mathrm{~A}$ ) and hydrolysis co-chromatographed with DL-3-hydroxypalmitic acid (see section 2.4.1) by radio-TLC and -GC. Purified 3-oxopalmitoyl-CoA (Figure $6 \mathrm{~B}$ and below) was quantitatively converted to L-3-hydroxypalmitoyl-CoA in the presence of NADH and L-3-hydroxyacyl-CoA:NAD ${ }^{+}$ oxido-reductase at $\mathrm{pH} 8.2$ as seen in Figure 4 (55). The purified 3-oxopalmitoyl-CoA also showed the characteristic spectrum of a magnesium enolate at $\mathrm{pH} 9.6(60)$.

The hydroxy and oxoacyl-CoA derivatives (Figure $6 \mathrm{~A}$ and B, respectively) were collected in Erlenmeyer flasks kept at $0{ }^{\circ} \mathrm{C}$. The $\mathrm{pH}$ of the collected eluate was adjusted to 2.0 by addition of $6 \mathrm{~N}-\mathrm{HCl}$. The fractions were taken to dryness using a rotary evaporator operated at $30^{\circ} \mathrm{C}$. The residue was dissolved in a 20 mM-sodium phosphate buffer and the $\mathrm{pH}$ adjusted to 5.7 with $0.4 \mathrm{M}-\mathrm{KHCO}_{3}$. Purified acyl$\mathrm{CoA}$ derivatives were fed immediately to barley tissue slices as described in section 2.6.

\subsection{Incorporation of labelled precursors and isolation of epicuticular lipids}

The incorporation conditions were essentially as described previously (43), but were optimized with respect to $\beta$-diketone synthesis as follows: 
Tissue slices prepared from two spikes with the awns removed were incubated with the appropriate substrate in $10 \mathrm{ml} 20 \mathrm{mM}$-sodium phosphate buffer at $\mathrm{pH}$ 5.7. Labelled alkan-1-ols, alkan-2-ols, methyl ketones as well as 3-hydroxy and normal fatty acids were dispersed in Tween20 by sonication (41). The total amount of Tween-20 in all experiments was $1 \mathrm{mg}$. The incubation was carried out for 2 hours at 17 ${ }^{\circ} \mathrm{C}$ in the light in the Weiss growth chamber specified above. The reaction was terminated by addition of $200 \mu \mathrm{l} 10 \mathrm{~N}-\mathrm{H}_{2} \mathrm{SO}_{4}$, and the epicuticular waxes were recovered by extraction with $30 \mathrm{ml} \mathrm{CHCl}{ }_{3}$ (43). Chloroform extracts were concentrated under a stream of nitrogen.

After an initial separation of the esters plus $\beta$-diketones on silica gel plates, they were separated on copper acetate TLC plates (41). Esters were either analyzed directly by radio-GC, or transesterified by treatment with $\mathrm{BF}_{3}$ in methanol (42). The ester fatty acids, as their methyl ester derivatives, and alcohols were separated by TLC before quantitation (42). Separation of the alkan-1-ol and alkan-2-ol moieties was accomplished by TLC after oxidation (76), which converted them into fatty acids and methyl ketones, respectively. The ester alcohols were dissolved in $1 \mathrm{ml}$ diethyl ether, $0.6 \mathrm{ml}$ saturated $\mathrm{K}_{2} \mathrm{Cr}_{2} \mathrm{O}_{7}: 10 \mathrm{~N}-\mathrm{H}_{2} \mathrm{SO}_{4}(5: 3, \mathrm{v} / \mathrm{v})$ was added and the solution incubated at $25^{\circ} \mathrm{C}$ for 20 hours. After addition of $2 \mathrm{ml}$ water, the reaction products were recovered by extraction with $5 \times 3 \mathrm{ml}$ diethyl ether. The combined organic phases were dried over anhydrous $\mathrm{Na}_{2} \mathrm{SO}_{4}$ before the solvent was removed by a gentle stream of nitrogen. To determine the chain lengths, non derivatized ester alcohols were analyzed by radio-GC using the Silar $10 \mathrm{C}$ column described in section 2.7 . The $\beta$-diketones were reduced to the corresponding $\beta$-diols (43) and converted to TMS derivatives by reaction with $200 \mu \mathrm{l}$ pyridine: N,N-bis-trimethylsilyltrifluoroacetamide: trimethylchlorosilane: trimethylsilylimidazole $(10: 10: 2: 1, \mathrm{v} / \mathrm{v})$ at $55^{\circ} \mathrm{C}$ for $30 \mathrm{~min}$. The $\beta$-diketones were also cleaved by the iodoform reaction (49), and the resulting fatty acid moieties were analyzed by radio-GC as their methyl ester derivatives.

\subsection{Radio-gas chromatography (radio-GC)}

Analyses were performed using a Packard Inc. (Downers Growe, Ill., USA) instrument $(3,43)$. The flows of the radio-GC for detection of ${ }^{14} \mathrm{C}$-labelled samples were the same as given (3). For ${ }^{3} \mathrm{H}$-labelled samples the flows of the radiogas chromatograph were adjusted so that flow of the helium carrier from the splitter to the flame ionization detector was $3.5 \mathrm{ml} \times \mathrm{min}^{-1}$ and from the splitter to the proportional counter $30.6 \mathrm{ml} \times \mathrm{min}^{-1}$. The flame ionization detector was operated with hydrogen and air flows to give optimal sensitivity. Quenching gas (propane) and hydrogen (for the reducing furnace) for the proportional counter were regulated by two Model 8286 pressure regulators (Porter Instrument Co., Hallfield, Penn., USA) to 4.8 and $8.4 \mathrm{ml} \times \mathrm{min}^{-1}$, respectively. The high voltage setting was 1750 volts. The signal from both the flame ionization and proportional counter were fed to a Hewlett-Packard Model 9825B Desktop Computer. Chromatographic data were stored on tapes, and integration of areas determined by a real-time program essentially as described by WOERLY and MOL (78), but modified to fit the Hewlett-Packard hardware by Mr. S. HoRSGARD (program available on request, Carlsberg Research Center).

Alkan-1-ol and alkan-2-ol esters were separated on stainless steel columns $162 \mathrm{~cm} \times 2 \mathrm{~mm}$ packed with either $1.5 \%$ Dexsil 300 on $60 / 80$ mesh Chromosorb W AW (Analabs, Conn., U.S.A.), or 3\% SP 2100 on $100 / 120$ mesh Sulpelcoport (Supelco Inc., Penn., U.S.A.). The column temperature was programmed from 210 ${ }^{\circ} \mathrm{C}$ at a rate of $2{ }^{\circ} \mathrm{C} \times \mathrm{min}^{-1}$ to $320^{\circ} \mathrm{C}$ at which temperature it was held for $15 \mathrm{~min}$. The injector port was maintained at $330{ }^{\circ} \mathrm{C}$ and the flame ionization detector at $360^{\circ} \mathrm{C}$. The $\beta$-diketones were analyzed as their $\beta$-diol TMS derivatives (43) on a $100 \mathrm{~cm} \times 2 \mathrm{~mm}$ glass column prepacked with $10 \%$ SE 30 on $80 / 100$ mesh Chromosorb W HP (Packard Inc., Ill., U.S.A.). The column temperature was programmed from 200 ${ }^{\circ} \mathrm{C}$ at a rate of $2{ }^{\circ} \mathrm{C} \times \min ^{-1}$ to $275^{\circ} \mathrm{C}$ at which temperature it was held for $10 \mathrm{~min}$. Fatty acid moieties from the cleavage of the $\beta$-diketones (49) were analyzed as their methyl ester derivatives on the SE 30 column using a temperature program of $140-250^{\circ} \mathrm{C}, 3^{\circ} \mathrm{C} \times \mathrm{min}^{-1}$. The ester 
TABLE 1.

Structural characterization of the TMS derivatives from 3-oxoacyl and 3-hydroxyacyl methyl esters.

\begin{tabular}{|c|c|c|c|c|c|c|c|c|c|}
\hline \multirow[t]{2}{*}{$\begin{array}{l}\text { Chain } \\
\text { lengths }\end{array}$} & \multirow[t]{2}{*}{$\begin{array}{l}\text { TMS } \\
\text { derivative }\end{array}$} & \multicolumn{8}{|c|}{$\begin{array}{l}\text { Important mass ion fragment } \\
\qquad \mathrm{m} / \mathrm{z}\end{array}$} \\
\hline & & 173 & 175 & 188 & 201 & $M-73$ & M-31 & M-15 & $\mathrm{M}(\mathrm{MW})$ \\
\hline & & & \multicolumn{7}{|c|}{ (Relative intensities, \%) } \\
\hline $12^{\mathrm{a}}$ & $3-0 \times 0$ & 100 & - & 23 & 36 & - & 10 & 35 & $4(300)$ \\
\hline $14^{b}$ & 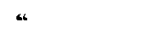 & 100 & - & 26 & 43 & - & 9 & 32 & $4(328)$ \\
\hline 16 & “ & 100 & - & 31 & 43 & - & 8 & 35 & $4(356)$ \\
\hline 18 & “ & 100 & - & 33 & 43 & - & 6 & 26 & $4(384)$ \\
\hline 14 & 3-hydroxy & - & 100 & - & - & 12 & 3 & 81 & $0(330)$ \\
\hline 16 & 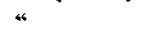 & - & 100 & - & - & 8 & 2 & 77 & $0(358)$ \\
\hline 18 & “ & - & 100 & - & - & 9 & 2 & 75 & $0(386)$ \\
\hline
\end{tabular}

a 3-oxododecanoic acid methyl ester served as a standard. It was synthesized from unlabelled decenoyl chloride and methyl acetoacetate as detailed by STOFFel and Pruss (63).

"The $C_{14}, C_{1 b}$ and $C_{18}$ compounds were synthesized as described in Section 2.4 .1 , using $\left(1-{ }^{14} \mathrm{C}\right)$-labelled lauric $\left(C_{12}\right)$, myristic $\left(C_{14}\right)$ and palmitic $\left(C_{16}\right)$ acids, respectively.

alcohol moieties and methyl ketones were analyzed on a $162 \mathrm{~cm} \times 2 \mathrm{~mm}$ stainless steel column packed with $10 \%$ Silar $10 \mathrm{C}$ on $100 / 120$ mesh Gas Chrom Q (Applied Science, Penn., U.S.A.) using a temperature program of $150-250{ }^{\circ} \mathrm{C}$, $2{ }^{\circ} \mathrm{C} \times \mathrm{min}^{-1}$.

\section{RESULTS}

\subsection{Structural identification of labelled} products formed by chemical synthesis

The structure of the 3-oxoacyl methyl esters was tentatively elucidated on the basis of chemical reactions detailed in Section 2.4.1, namely: i) positive reaction with phenylhydrazine, ii) reduction with $\mathrm{NaBH}_{4}$ to yield the DL-3-hydroxy fatty acid derivative and iii) decarboxylation to form the methyl ketone. To confirm the structure of the 3-oxoacyl methyl esters, the TMS ether of the enol form was prepared for analysis by GC-MS. Hereafter they will be referred to as oxo-TMS derivatives. The important mass ion fragments are given in Table I. A relatively small molecular ion peak $\left(\mathbf{M}^{+}\right)$ was observed which together with the intense $\mathrm{m} / \mathrm{z}$ fragments peaks $\mathrm{M}-15\left(\mathrm{M}-\mathrm{CH}_{3}\right)$ and $\mathrm{M}-31$ $\left(\mathrm{M}-\mathrm{OCH}_{3}\right)$ allows assignment of the molecular formula, $\mathrm{C}_{n} \mathrm{H}_{2 \mathrm{n}} \mathrm{O}_{3} \mathrm{Si}$. The most prominent peak at $\mathrm{m} / \mathrm{z} 173$ arises from a simple cleavage alpha to the TMS group between carbon atoms 3 and 4 (Figure 8, upper). Beta or gamma cleavage between carbon atoms 4 and 5 or 5 and 6 yields the $\mathrm{m} / \mathrm{z}$ fragments at 188 and 201 , respectively.

GC-MS analysis was also performed on the TMS derivatives of the DL-3-hydroxy fatty acid methyl esters. The results are included in Table I. The fragmentation pattern is very similar to that described above for the oxo-TMS derivatives. No molecular ion peaks were observed, however, but this was compensated for by the increase in size of the $M-15 \mathrm{~m} / \mathrm{z}$ peaks. The M-31 peaks were also less intense. In contrast to the oxo-TMS derivatives, two alpha cleavage peaks $\mathrm{CH}_{3} \mathrm{COOCH}_{2} \mathrm{CHO}^{+} \mathrm{SiMe}_{3}$ and $\mathrm{CH}_{3}\left(\mathrm{CH}_{2}\right)_{x} \mathrm{CHO}^{+} \mathrm{SiMe}_{3}$ were observed (Figure 8, lower). The peak for the former ion at $\mathrm{m} / \mathrm{z} 175$ was by far the most prominent in these spectra. The increase in molecular weight by two compared to the corresponding oxo-TMS alpha cleavage fragment is expected. No significant beta and gamma cleavage was observed with the TMS derivative of the DL-3-hydroxy fatty acid methyl esters. The observed MS fragmentation pattern is in agreement with the results reported by EGLINTON et al. (17) and KAWAMURA and ISHIWATARI (28) for 3-hydroxy fatty acids in recent sediments. 


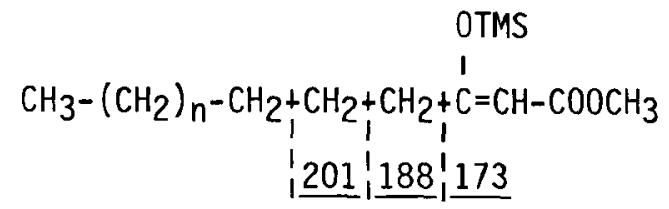

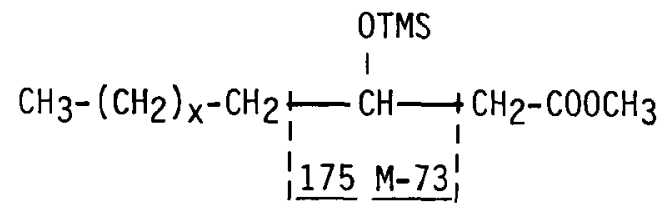

Figure 8. Origin of the important mass ion fragments in the mass spectra of the TMS derivatives of 3-oxo (upper) and DL-3-hydroxy (lower) fatty acid methyl esters. $\mathrm{n}=5,7,9$ and $11 ; \mathrm{x}=9,11$ and 13 .

\subsection{Structural characterization of $\left(1-{ }^{14} \mathrm{C}\right)$ - 10,12-dioxoeicosanoic acid}

The presence of a $\beta$-diketone group in the $\left(1-{ }^{14} \mathrm{C}\right)$-10,12-dioxoeicosanoic acid molecule was initially indicated by its color reaction with ferric ions and its ability to form a chelate with copper acetate. The ultraviolet absorption spectrum in hexane is also identical to that obtained for the $\beta$-diketones (primarily hentriacontan- 14,16-dione) isolated from barley epicuticular wax (43). Further structural identification was carried out by GC-MS analysis. The $\beta$-diketo fatty acid was analyzed directly as a methyl ester derivative or after further derivation to a dimethoxim or $\beta$-diol TMS. The important fragments obtained by these GC-MS analyses are given in Table II. A rather complex mode of cleavage is observed when the $\beta$-diketo group is not modified before GC-MS. The molecular ion peak at $\mathrm{m} / \mathrm{z} 354$ (Table II, line 2; Figure 9, II) was weak but sufficient to assign the molecular formula. Location of the $\beta$-diketo groups depends upon four alpha cleavage points, giving rise to the four fragments at 141,183 , 199 and 241. Peaks at $\mathrm{m} / \mathrm{z} 198$ and 256 are due to McLafferty rearrangements (40). The most prominent mass ion at $\mathrm{m} / \mathrm{z} 100$ is characteristic for $\beta$-diketones and its formation has been discussed in great detail by TRKA and STREIBL (66). The mass fragmentation pattern of the $C_{19} \beta$-diketo fatty acid methyl ester (Table II, line 1 ; Figure 9,1 ) is identical to that described previously by HOOPER and LAW (24) and MCCloskey (40).

By comparison the fragmentation patterns of the dimethoxim and the $\beta$-diol TMS derivatives were much simpler (Figure 9, III, IV, and V).

TABLE II.

Identification of the methyl ester of $\left(1-{ }^{14} \mathrm{C}\right)-10,12-$ dioxoeicosanoic acid by GC-MS analyses".

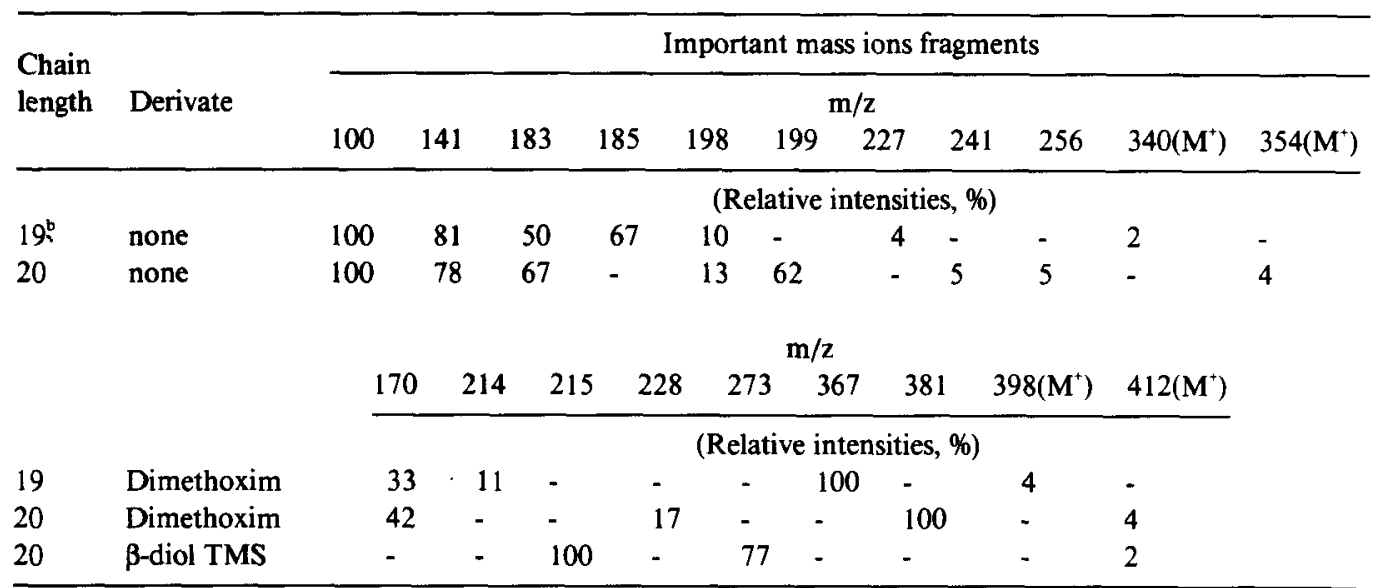

"Analysed as the methyl esters directly or as the dimethoxim or $\beta$-diol TMS derivatives. Structures and origin of fragments are shown in Figure 9 and/or detailed in the text.

${ }^{b}$ The $C_{19}$ homologue was isolated from Sterculia foetida seeds as detailed in section 2.4 .3 and is included in the Table as a standard. 
A relative weak molecular ion peak was observed for both types of derivatives (Table II). The dimethoxim derivative readily eliminates a methoxy group (M-31) giving rise to peaks at $\mathrm{m} / \mathrm{z}$ 381 and 367 for the $C_{20}$ and $C_{19}$ homologues, respectively. The characteristic alpha cleavage points on both sides of either carbon atom 10 or 11 for the $C_{19}$ and $C_{20}$ homologues, respectively, conclusively localize the original $\boldsymbol{\beta}$-dicarbonyl groups (Figure 9, III and IV). It should be noted that the relative intensities of these alpha mass ion fragments for the $\beta$-diol TMS derivatives at $\mathrm{m} / \mathrm{z} 215$ and 273 (Table II, line 5) are significantly higher than those formed from the corresponding $\mathrm{C}_{20}$ dimethoxim derivatives at $\mathrm{m} / \mathrm{z} 170$ and 228 . Chemical degradation of $\left(1-{ }^{14} \mathrm{C}\right)-10,12$-dioxoeicosanoic acid by the iodoform reaction yielded a labelled compound, which was identified by GC-MS analyses as sebacic acid (decandicarboxylic acid, $\mathrm{C}_{10}$ ). These analyses unequivocally identify the $C_{20} \beta$-diketo fatty acid as $\left(1-{ }^{14} \mathrm{C}\right)-10,12$,-dioxoeicosanoic.

\subsection{Incorporation of labelled precursors into $\beta$-diketones and esters}

The same rate of $\beta$-diketone synthesis was observed when tissue slices prepared from cer$u^{69}$ spikes minus the awns were fed $\left(9,10{ }^{3} \mathrm{H}\right)$-labelled palmitoyl-CoA or 3-oxopalmitoyl-CoA (see Table III). In contrast $\left(9,10-{ }^{3} \mathrm{H}\right)$-L-3-hydroxypalmitoyl-CoA was 10 times less effectively incorporated. A five-fold increase occurred in the amounts (nmol) of labelled $\beta$-diketones synthesized when palmitoyl-CoA was labelled with ${ }^{14} \mathrm{C}$ instead of ${ }^{3} \mathrm{H}$. This result is probably due to the marked difference in both the specific activities of these two substrates, 6.7 and 61.2 $\mathrm{mCi} \times \mathrm{mmol}^{-1}$ for the ${ }^{14} \mathrm{C}$-and ${ }^{3} \mathrm{H}$-labelled $\mathrm{CoA}$ derivatives, respectively, and the different amounts given to the tissue slices. Increased binding to the tissue slices as well as to the incubation flask seems to occur, as the specific activities increase, and reduces the amount of substrate available for synthesis. An analogous difference can be noted in feeding experiments using $\left(1-{ }^{14} \mathrm{C}\right)$-myristic acid vs its $\mathrm{CoA}$ derivative having specific activities of 45 and 6.9 $\mathrm{mCi} \mathrm{mmol}^{1}$, respectively (Table III). Due to this complication comparison of rates of syn-
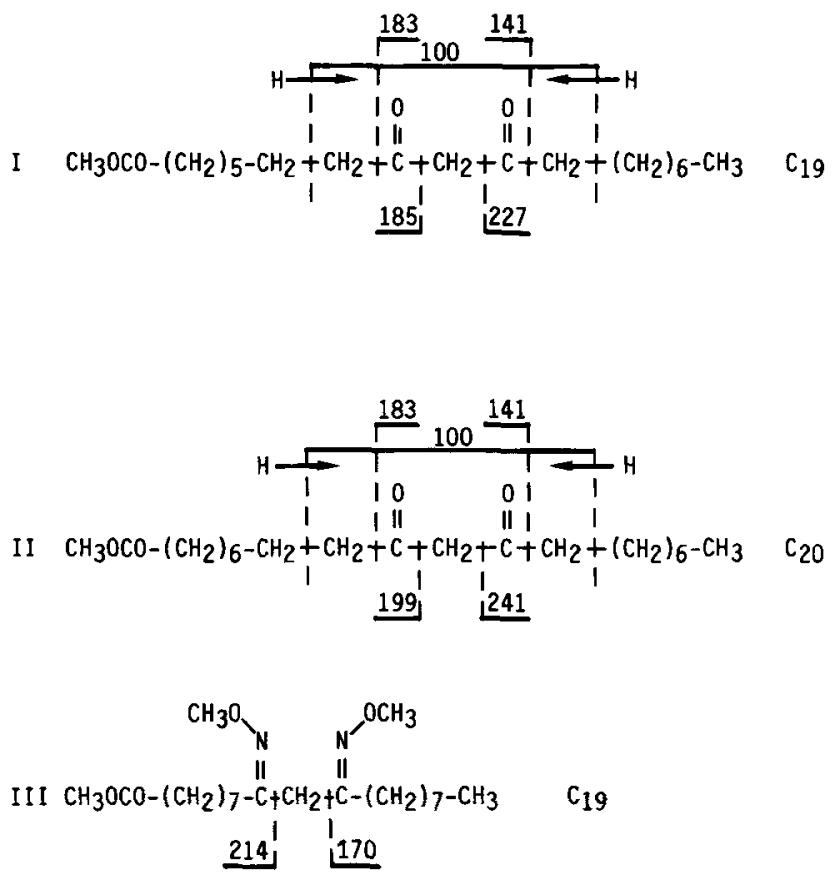

$\mathrm{C}_{20}$

Figure 9. Origin of the important mass ion fragments of the $\beta$-diketo fatty acid methyl esters, their dimethoxim and $\beta$-diol TMS derivatives. $I=9,11$-dioxononadecanoate, $\mathrm{II}=10,12$-dioxoeicosanoate, III and IV are the dimethoxim derivatives of I and II, respectively. V $=$ TMS derivative of II after treatment with $\mathrm{NaBH}_{4}$.

theses can only be drawn among experiments where the substrates have similar specific activities. In marked contrast to the ${ }^{3} \mathrm{H}$-labelled $\mathrm{CoA}$ results, incorporation of $\left(1-{ }^{14} \mathrm{C}\right)-3$-oxopalmitoyl-CoA into the $\beta$-diketones was more than three-fold lower than that of $\left(1-{ }^{14} \mathrm{C}\right)$-palmitoylCoA. Only very low amounts of radioactivity were incorporated into the $\beta$-diketones when 
TABLE III .

Synthesis of $\beta$-diketones and esters by tissue slices prepared from barley spikes minus the awns fed various labelled precursors"

\begin{tabular}{|c|c|c|c|c|c|c|}
\hline \multirow[t]{2}{*}{ Genotype } & \multirow[t]{2}{*}{ Substrate } & \multirow{2}{*}{$\begin{array}{l}\mu \mathrm{Ci} \\
\text { fed }\end{array}$} & \multicolumn{2}{|c|}{$\beta$-diketones } & \multicolumn{2}{|c|}{ Esters $^{\mathrm{b}}$} \\
\hline & & & nmol & $\mathrm{dpm} \times 10^{-4}$ & $\mathrm{nmol}$ & $\mathrm{dpm} \times 10^{-4}$ \\
\hline $\operatorname{cer}-u^{69}$ & $\left(9,10 \cdot{ }^{3} \mathrm{H}\right)$-palmitoyl-CoA & 10.8 & 1.9 & 26 & 5.9 & 79.8 \\
\hline$-c^{36}$ & “ & “ & 0 & 0 & 3.0 & 40.8 \\
\hline$-q^{42}$ & “ & “ & 0 & 0 & 3.0 & 41.0 \\
\hline$-u^{69}$ & $\left(9,10-{ }^{3} \mathrm{H}\right)-\mathrm{L}-3-\mathrm{OH}$-palmitoyl-CoA & 10.8 & 0.2 & 2.5 & 0.4 & 5.1 \\
\hline$-c^{36}$ & “ & “ & 0 & 0 & 0.3 & 4.1 \\
\hline$-q^{42}$ & “ & “ & 0 & 0 & 0.2 & 3.0 \\
\hline$-u^{69}$ & $\left(9,10-^{3} \mathrm{H}\right)-3$-oxopalmitoyl-CoA & 8.8 & 2.1 & 27.9 & 11.1 & 150 \\
\hline$-c^{36}$ & “ & “ & $\mathbf{0}$ & 0 & 7.6 & 102 \\
\hline$-q^{42}$ & “ & “ & 0 & 0 & 7.7 & 104 \\
\hline$-u^{69}$ & $\left(1-{ }^{14} \mathrm{C}\right)$-palmitoyl-CoA & 9.9 & 12.6 & 18.6 & 18.9 & 27.8 \\
\hline$-u^{69}$ & $\left(1-{ }^{14} \mathrm{C}\right)-3$-oxopalmitoyl-CoA & 9.8 & 2.9 & 4.3 & 3.4 & 5.0 \\
\hline$-u^{69}$ & $\left(1-{ }^{14} \mathrm{C}\right)$-myristic acid & 10.0 & 4.0 & 50.0 & 4.1 & 52 \\
\hline$-u^{69}$ & $\left(1-{ }^{14} \mathrm{C}\right)$-myristoyl-CoA & 5.0 & 18.1 & 27.6 & 21.5 & 32.7 \\
\hline$-u^{69}$ & $\left(3-{ }^{14} \mathrm{C}\right)-\mathrm{DL}-3-\mathrm{OH}$-palmitate & 10.0 & 0.5 & 1.2 & 1.1 & 2.5 \\
\hline$-c^{36}$ & “ & " & 0 & 0 & 1.4 & 3.1 \\
\hline$-q^{42}$ & “ & “ & 0 & 0 & 1.3 & 2.8 \\
\hline$-u^{69}$ & $\left(2-{ }^{14} \mathrm{C}\right)$-pentadecan-2-one & 9.8 & 0 & 0 & 117 & 259 \\
\hline$-c^{36}$ & “ & “ & 0 & 0 & 48.2 & 106 \\
\hline$-q^{42}$ & “ & “ & 0 & 0 & 80.0 & 176 \\
\hline$-u^{69}$ & $\left(10,11-{ }^{3} \mathrm{H}\right)$-heptadecan-2-one & 10.0 & 0 & 0 & 11.1 & 24.4 \\
\hline$-c^{36}$ & “ & “ & 0 & 0 & 6.7 & 14.8 \\
\hline$-q^{42}$ & “ & “ & 0 & 0 & 15.7 & 34.6 \\
\hline$-c^{36}$ & (2- $\left.{ }^{3} \mathrm{H}\right)$-pentadecan-2-ol & 50.0 & 0 & 0 & 40.8 & 226 \\
\hline$-q^{36}$ & “ & 50.0 & 0 & 0 & 44.4 & 246 \\
\hline$-c^{36}$ & $\left(1 .{ }^{14} \mathrm{C}\right)$-octadecanol & 5.0 & 0 & 0 & 5.1 & 63.5 \\
\hline$-q^{42}$ & “ & “ & 0 & 0 & 4.3 & 53.0 \\
\hline
\end{tabular}

2Procedures for isolation and quantitation of the labelled epicuticular wax classes are given in Materials and Methods and (references 3, 41, 43).

' The ester fraction can be composed of both alkan-1-ol and alkan-2-ol esters.

(3- $\left.{ }^{14} \mathrm{C}\right)-\mathrm{DL}-3-$ hydroxy fatty acids with chain lengths of 14,16 and 18 carbon atoms were used as the substrate (only the result for the $\mathrm{C}_{16}$ homologue is given in Table III). Repeated incorporation experiments using tissue slices from $c e r-u^{69}$ and $\left(1-{ }^{14} \mathrm{C}\right)-10,12$-dioxoeicosanoic acid failed to yield any labelled $\beta$-diketones, similarly to the remaining tested substrates listed in Table III. Feeding $\left(1-{ }^{14} \mathrm{C}\right)-10,12$-dioxoeicosanoic acid did not give any other labelled wax class either.

Whereas $c e r-u^{69}$ was capable of synthesizing $\beta$-diketones from all the above precursors $c e r-c^{36}$ and $-q^{42}$ were totally inactive (Table III) as might be expected from the in vivo compositional analysis (73). All three mutants, however, synthesized esters (see Table III). The rate of ester synthesis for $c e r-u^{69}$ was almost double that for $c e r-c^{36}$ and $-q^{42}$ when $\left(9,10-{ }^{3} \mathrm{H}\right)$-palmitoyl-CoA was fed to the tissue slices. A similar relationship between $c e r-u^{69}$ and the other two mutants was also observed with $\left(9,10-{ }^{3} \mathrm{H}\right)$-3-oxopalmitoylCoA. The total amounts of label in the esters for all three mutants were roughly twice as much with the latter precursor than with $\left(9,10-{ }^{3} \mathrm{H}\right)$-palmitoyl-CoA. (9,10- $\left.{ }^{3} \mathrm{H}\right)$-L-3-hydroxypalmitoylCoA and $\left(3-{ }^{14} \mathrm{C}\right)$-DL-3-hydroxypalmitic acid were equally poor substrates for the esters as they were for the $\beta$-diketones. More than 10 times less label was incorporated into the esters 


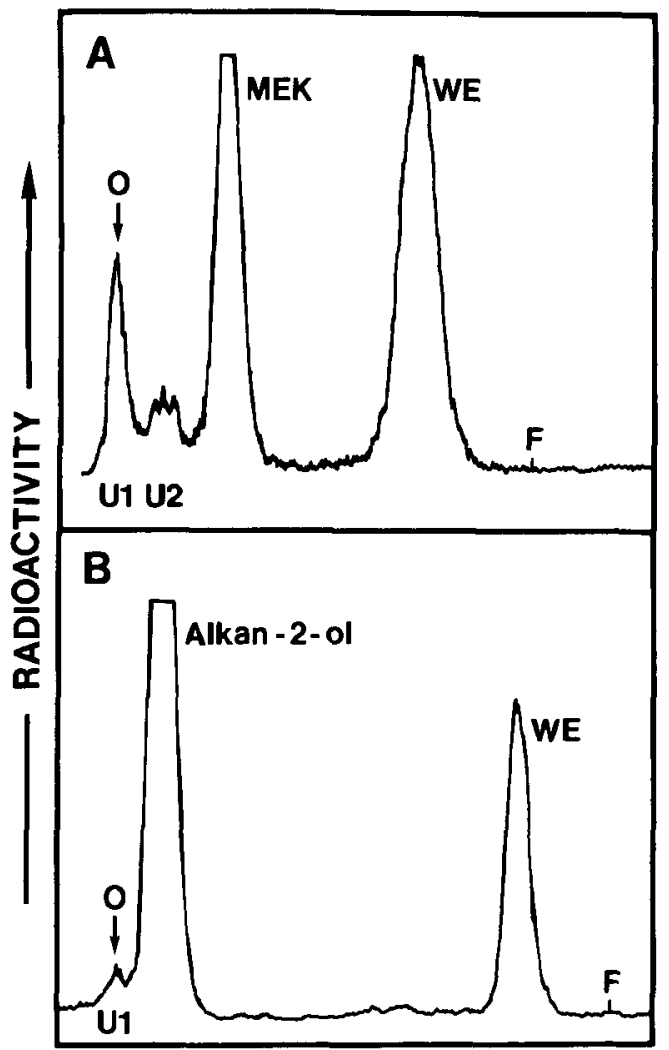

Figure 10. Radio-thin layer chromatogram of the epicuticular wax from cer- $\mathrm{c}^{36}$ spikes minus the awns fed with $\left(2-{ }^{14} \mathrm{C}\right)$-pentadecan-2-one $(\mathrm{A})$ or $\left(2-{ }^{3} \mathrm{H}\right)$-pentadecan-2-ol (B). WE $=$ wax ester synthesized, $\mathrm{MEK}=$ methyl ketone $\left(\left(2-{ }^{14} \mathrm{C}\right)\right.$-pentadecan-2-one $)$ not metabolized, alkan-2-ol $=\left(2-{ }^{3} \mathrm{H}\right)$-pentadecan-2-ol not metabolized, $\mathrm{U} 1$ and $\mathrm{U} 2=\mathrm{Unknowns}, \mathrm{O}=$ origin, $\mathrm{F}=$ solvent front. $\mathrm{A}$ and $\mathrm{B}$ were both developed in $\mathrm{CHCl}_{3}$ stabilized with amylene.

using the ${ }^{3} \mathrm{H}$-labelled hydroxyacyl-CoA derivative as compared with $\left(9,10-{ }_{-}^{3} \mathrm{H}\right)$-palmitoyl-CoA.

The rate of ester synthesis was highest for cer- $u^{69}$ when $\left(2-{ }^{14} \mathrm{C}\right)$-pentadecan-2-one was used as the substrate. By comparison $c e r-c^{36}$ and $-q^{42}$ incorporated 41 and $69 \%$ as much label into the esters, respectively, when this substrate was used. In fact almost $12 \%$ of the total $\left(2-{ }^{14} \mathrm{C}\right)$-pentadecan-2-one fed to cer- $u^{69}$ tissue slices was recovered in the esters. The corresponding figure for $\left(9,10{ }^{3} \mathrm{H}\right)$-palmitoyl-CoA is $3.4 \%$. Whereas the latter substrate was incorporated into at least seven epicuticular wax components, the hydrocarbons, alkan-1-ol and alkan-2-ol esters, $\beta$-di- ketones, aldehydes, primary alcohols and long chain fatty acids $(41),\left(2 \cdot{ }^{14} \mathrm{C}\right)$-pentadecan-2-one was essentially present only in the esters (Figure $10 \mathrm{~A}) \cdot\left(10,11^{3} \mathrm{H}\right)$-heptadecan-2-one was a less efficient precursor for ester synthesis than the $\mathrm{C}_{15}$ homologue. Taking into account the different amounts of radioactivity fed to the tissue slices, then only 9,14 and $19 \%$ as much was incorporated from the $\mathrm{C}_{17}$ methyl ketone by $c e r-u^{69},-c^{36}$ and $-q^{42}$, respectively. High amounts of label were also present in the esters when (2- $\left.{ }^{3} \mathrm{H}\right)$-pentadecan-2-ol was used (Table III). This precursor is specifically incorporated into the esters (Figure 10B). No significant difference was detected between $c e r-c^{36}$ and $-q^{42}$ in their capacity to synthesize esters from $\left(2-{ }^{3} \mathrm{H}\right)$-pentadecan-2-ol or $\left(1-{ }^{14} \mathrm{C}\right)$-octadecan-1-ol.

\subsection{Determination of the labelling pattern in the $\beta$-diketone molecules}

To investigate the mode of $\beta$-diketone synthesis, the $\beta$-diketones labelled with selected precursors were isolated by preparative TLC. The distribution of radioactivity among the various chain lengths was determined by radioGC analyses of their $\beta$-diol TMS derivatives. Incorporation of $\left(1-{ }^{14} \mathrm{C}\right)$ - and $\left(9,10-{ }^{3} \mathrm{H}\right)$-labelled palmitoyl-CoA as well as $\left(1-{ }^{14} \mathrm{C}\right)$-3-oxopalmitoyl-CoA into the $\beta$-diketones gave distributions of radioactivity very similar to the mass distribution (Table IV). The proportion of radioactivity in the $\mathrm{C}_{29} \beta$-diketone was drastically increased to 35 and $58 \%$ of the total when $\left(9,10-{ }^{3} \mathrm{H}\right)$-3-oxopalmitoyl-CoA and $\left(1-{ }^{14} \mathrm{C}\right)$-myristic acid, respectively, were used as substrates.

The mode by which these selected precursors were incorporated into the two ends of the $\beta$-diketone molecules was also examined. This necessitated the cleavage by the iodoform reaction of the mixture of $\beta$-diketones synthesized from each given substrate (49). The resulting mixture of fatty acid moieties from each experiment were analysed by radio-GC as their methyl ester derivatives (Table V). The two palmitoyl-CoA substrates labelled almost exclusively the $C_{16}$ fatty acid moieties of the $\beta$-diketones, although some radioactivity was observed in the $C_{15}$ fatty acid moiety when the ${ }^{3} \mathrm{H}$-labelled precursor was employed. The radio- 
TABLE IV.

Distribution of radioactivity in $\beta$-diketones isolated from tissue slices prepared from the spikes minus the awns of the mutant $c^{-e r-u^{69}}$ fed various labelled precursors".

\begin{tabular}{lcccc}
\hline Substrate & \multicolumn{3}{c}{$\beta$-diketones } & $\begin{array}{c}\text { Total dpm } \\
\text { injected }^{\mathrm{b}}\end{array}$ \\
\cline { 2 - 5 } & $\mathrm{C}_{29}$ & $\mathrm{C}_{31}$ & $\mathrm{C}_{33}$ & \\
& 0.4 & $\begin{array}{c}\text { (weight \%) } \\
\text { (radioactivity \%) }\end{array}$ & 3.8 \\
$\left(9,10-{ }^{3} \mathrm{H}\right.$ )-palmitoyl-CoA & tr & 97.6 & 2.5 & 42,400 \\
$\left(1-^{14} \mathrm{C}\right.$ )-palmitoyl-CoA & 0 & 99.1 & 0.9 & 25,900 \\
$\left(1-^{14} \mathrm{C}\right)-3$-oxopalmitoyl-CoA & 3.1 & 95.2 & 1.7 & 28,200 \\
$\left(9,10-{ }^{-} \mathrm{H}\right.$ )-3-oxopalmitoyl-CoA & 34.6 & 64.2 & 1.2 & 53,800 \\
$\left(1-^{14} \mathrm{C}\right)$-myristic acid & 57.6 & 41.3 & 1.1 & 33,500 \\
\hline
\end{tabular}

" The $\beta$-diketones were isolated from as many as five incorporation experiments and aliquots analysed as their $\beta$-diol TMS derivatives.

${ }^{b}$ The total dpm in a single injection was calculated using the calibration procedure of NETTING and BARR (50).

'Data from reference 43

$\operatorname{tr}<200 \mathrm{dpm}$

active distributions observed with these two precursors are identical to that previously presented for the corresponding free fatty acids (43). Increasing amounts of radioactivity in the $\mathrm{C}_{14}$ fatty acid moieties were observed when the 3-oxopalmitoyl-CoA substrates substituted for the normal acyl-CoA homologues. The radioactive distribution for $\left(9,10-{ }_{-}^{3} \mathrm{H}\right)$-3-oxopalmitoyl-CoA almost mimicked that given for (1$\left.{ }^{14} \mathrm{C}\right)$-myristic acid.
3.5. Distribution of radioactivity in alkan-2-ol containing esters labelled with various precursors

To determine specifically how the different substrates may label the alkan-2-ol esters, the wax ester fraction, composed of both the alkan1-ol and alkan-2-ol containing esters, was eluted as a single band from preparative TLC plates. The distribution of radioactivity among the various chain lengths of both ester classes was

TABLE $V$.

Distribution of label among fatty acid moieties obtained by the cleavage of the $\beta$-diketones synthesized from various labelled precursors".

\begin{tabular}{|c|c|c|c|c|c|}
\hline \multirow{2}{*}{ Substrate } & \multicolumn{4}{|c|}{ Fatty acid moieties } & \multirow{2}{*}{$\begin{array}{l}\text { Total dpm } \\
\text { injected }{ }^{\mathrm{b}}\end{array}$} \\
\hline & $\mathrm{C}_{13}$ & $\mathrm{C}_{14}$ & $\mathrm{C}_{15}$ & $\mathrm{C}_{16}$ & \\
\hline & \multicolumn{4}{|c|}{$(\mathrm{mol} \%)^{\mathrm{c}}$} & \\
\hline & 2.3 & $\begin{array}{r}43.7 \\
(\mathrm{rad}\end{array}$ & & 49.9 & \\
\hline (1- $\left.{ }^{14} \mathrm{C}\right)$-palmitoyl-CoA & $\mathbf{0}$ & 0 & 0 & 100 & 23,500 \\
\hline$\left(1-{ }^{-4} \mathrm{C}\right)$-3-oxo-palmitoyl-CoA & 0.1 & 22.3 & 0.7 & 76.9 & 25,200 \\
\hline$\left(9,10-{ }^{3} \mathrm{H}\right)$-palmitoyl-CoA & 0 & 1.1 & 5.7 & 93.2 & 45,800 \\
\hline$\left(9,10-{ }^{3} \mathrm{H}\right)-3$-oxopalmitoyl-CoA & 1.4 & 59.3 & 2.2 & 37.3 & 53,700 \\
\hline$\left(1-{ }^{14} \mathrm{C}\right)$-myristic acid & 0 & 78.3 & 0.9 & 20.8 & 22,100 \\
\hline
\end{tabular}

Data are for aliquots from the same incorporation experiments analysed in Table IV.

${ }^{\circ}$ See legend $b$ of Table IV.

'The amount of a fatty acid in nmol was determined by the method of NETTING and BARR (50). $\mathrm{C}_{12}$ accounts for $1 \%$.

${ }^{d}$ The labelling patterns of the fatty acids were determined by radio-GC of their methyl ester derivatives. 
Table VI.

Distribution of label in alkan-2-ol containing esters synthesized from various labelled precursors".

\begin{tabular}{|c|c|c|c|c|c|c|c|c|}
\hline \multirow{2}{*}{ Genotype } & \multirow{2}{*}{ Substrate } & \multicolumn{7}{|c|}{ Chain Lengths } \\
\hline & & $\mathrm{C}_{27}$ & $\mathrm{C}_{29}$ & $\mathrm{C}_{31}$ & $\mathrm{C}_{33}$ & $\mathrm{C}_{35}$ & $\mathrm{C}_{37}$ & $\mathrm{C}_{39}$ \\
\hline & & \multicolumn{7}{|c|}{ (weight \%) } \\
\hline & & 0 & 0 & 5.5 & 34.4 & 49.3 & 10.8 & 0 \\
\hline & & \multicolumn{7}{|c|}{$(\text { radioactivity } \%)^{c}$} \\
\hline$c e r-u^{69}$ & (9,10- $\left.{ }^{3} \mathbf{H}\right)$-3-oxopalmitoyl-CoA & 0 & 0 & 4.6 & 38.6 & 50.5 & 5.9 & 0.3 \\
\hline$-c^{36}$ & “ & 0 & 0 & 8.3 & 40.2 & 44.6 & 6.3 & 0.5 \\
\hline$-q^{42}$ & “ & $\mathbf{0}$ & 0 & 1.4 & 39.2 & 56.4 & 3.1 & 0 \\
\hline$-u^{69}$ & $\left(2-{ }^{14} \mathrm{C}\right)$-pentadecan-2-one & 0 & 0 & 16.8 & 47.3 & 31.6 & 4.3 & 0 \\
\hline$-c^{36}$ & " & $\mathbf{0}$ & 0 & 12.5 & 46.2 & 33.1 & 8.1 & 0 \\
\hline$-q^{42}$ & “ & 0 & 0 & 16.5 & 49.7 & 29.6 & 4.3 & 0 \\
\hline$-u^{69}$ & $\left(10,11-{ }^{3} \mathrm{H}\right)$-heptadecan-2-one & 0 & 0 & 1.1 & 10.4 & 57.2 & 29.2 & 2.1 \\
\hline$-c^{36}$ & “ & 0 & 0 & 0.8 & 14.2 & 56.3 & 26.8 & 1.9 \\
\hline$-q^{42}$ & “ & 0 & 0 & 0 & 7.0 & 56.2 & 33.2 & 1.9 \\
\hline$-u^{69}$ & (2-- ${ }^{3}$ )-pentadecan-2-ol & 1.0 & 1.9 & 68.1 & 23.1 & 5.4 & 0.5 & 0 \\
\hline$-c^{36}$ & “ & 2.3 & 2.3 & 64.1 & 23.0 & 7.4 & 0.8 & 0.3 \\
\hline$-q^{42}$ & “ & $\mathbf{0}$ & 0 & 50.3 & 36.5 & 12.2 & 0.9 & 0 \\
\hline$-u^{69}$ & $\left(9,10-{ }^{3} \mathrm{H}\right)$-palmitoyl-CoA & 0 & 25.2 & 14.6 & 3.3 & 13.4 & 0 & 0 \\
\hline$-c^{36}$ & “ & 0 & 11.6 & 13.4 & 7.0 & 19.6 & 0 & 0 \\
\hline$-q^{42}$ & “ & 0 & 0 & 0 & 0 & 0 & 0 & 0 \\
\hline$-u^{69}$ & $\left(1-{ }^{14} \mathrm{C}\right)$-myristic acid & 0 & 0.9 & 2.1 & 11.8 & 16.2 & 0 & 0 \\
\hline
\end{tabular}

"The alkan-1-ol and alkan-2-ol esters were purified by preparative radio-TLC and analyzed by radio-GC.

${ }^{6}$ Data from reference 39.

' Radioactivity in the individual alkan-2-ol esters is presented as \% of that in the total ester fraction. The distribution of label in a single injection is based on a minimum of $30,000 \mathrm{dpm}$ for ${ }^{14} \mathrm{C}$ and $50,000 \mathrm{dpm}$ for ${ }^{3} \mathrm{H}$ (see legend b of Table IV).

then determined by radio-GC analysis. The results for the alkan-2-ol esters are presented in Table VI. When $\left(9,10-{ }^{3} \mathrm{H}\right)-3$-oxopalmitoylCoA was used as the substrate, the labelling pattern for the alkan-2-ol containing esters matched that of the in vivo chain length distribution of the alkan-2-ol containing esters. In all three mutants the $\mathrm{C}_{33}$ and $\mathrm{C}_{35}$ chain lengths predominated, containing from 85 to $96 \%$ of the total radioactivity present in the ester fraction. The $C_{35}$ homologue was always more strongly labelled than the $\mathrm{C}_{33}$ homologue. Smaller amounts of label were also present in the $\mathrm{C}_{31}, \mathrm{C}_{37}$ and $\mathrm{C}_{39}$ homologues. When $\left(2-{ }^{14} \mathrm{C}\right)-$ pentadecan-2-one was used the $C_{33}$ and $C_{35}$ alkan-2-ol esters again accounted for the major amount of the radioactivity although the proportion was slightly reduced to $79 \%$. In contrast to the experiments with the 3-oxopalmitoylCoA precursor, the highest amounts of label from $\left(2{ }^{14} \mathrm{C}\right)$-pentadecan-2-one were in the $\mathrm{C}_{33}$ instead of $\mathrm{C}_{35}$ homologue. Increased proportions of radioactivity were also observed in the $C_{31}$ alkan-2-ol ester. These changes were compensated for by 19,12 and $27 \%$ decreases of the amounts of label present in the $\mathrm{C}_{35}$ esters from cer- $u^{69},-c^{36}$ and $-q^{42}$, respectively. In the experiments with $\left(10,11-{ }^{3} \mathrm{H}\right)$-heptadecan-2-one $\left(\mathrm{C}_{17}\right)$, the whole spectrum of the ester chain lengths is displaced two carbon atoms towards the longer chain homologues as compared with the experiments using the $C_{15}$ methyl ketone as the precursor (Table VI). Interestingly, the distribution of radioactivity among the $C_{31}, C_{33}$ and $C_{35}$ chain lengths approaches that observed for the $\mathrm{C}_{33}, \mathrm{C}_{35}$ and $\mathrm{C}_{37}$ alkan-2-ol esters, when the results for the $\mathrm{C}_{15}$ and $\mathrm{C}_{17}$ methyl ketone precursors, respectively, are compared (Table VI). The labelling of the shorter chain ester homologues by the $\mathrm{C}_{15}$ methyl ketone compared to $\left(9,10{ }_{-}^{3} \mathrm{H}\right)$ - 
TABLE VII.

Distribution of label in fatty acid and alcohol moieties from esters labelled with various precursors"

\begin{tabular}{llccc}
\hline & & \multicolumn{3}{c}{ \% Radioactivity } \\
\cline { 3 - 5 } Genotypes & Substrate & Alkan-1-ols & Alkan-2-ols & Fatty acids \\
\hline$c e r-u^{69},-c^{36},-q^{42}$ & $\left(9,10-{ }^{3} \mathrm{H}\right)-3-$-oxopalmitoyl-CoA & 0 & 100 & 0 \\
$-u^{69},-c^{36},-q^{42}$ & $\left(2-{ }^{4} \mathrm{C}\right)$-pentadecan-2-one & 0 & 100 & 0 \\
$-u^{69},-c^{36},-q^{42}$ & $\left(9,10-{ }^{3} \mathrm{H}\right)$-heptadecan-2-one & 0 & 100 & 0 \\
$-u^{59},-c^{36},-q^{42}$ & $\left(2 \cdot{ }^{3} \mathrm{H}\right)$-pentadecan-2-ol & 0 & $100^{\mathrm{b}}$ & 0 \\
$-c^{36},-q^{42}$ & $\left(1-{ }^{4} \mathrm{C}\right)$-octadecan-1-ol & 100 & 0 & 0 \\
$-u^{69}$ & $\left(9,10-{ }^{39} \mathrm{H}\right)$-palmitoyl-CoA & 5.2 & 1.0 & 93.8 \\
$-c^{36}$ & $"$ & 6.0 & 1.1 & 92.9 \\
$-q^{42}$ & “ & 16.5 & 0 & 83.5 \\
$-u^{69}$ & $\left(1-{ }^{14} \mathrm{C}\right)$-myristic acid & 7.5 & 15.0 & 77.5 \\
\hline
\end{tabular}

" The ester fraction was transmethylated with $\mathrm{BF}_{3}$ in methanol, and the resulting fatty acid methyl ester and alcohol moieties were separated by TLC and quantitated. Alkan-1-ol and alkan-2-ol moieties were subjected to $\mathrm{K}_{2} \mathrm{CrO}_{7}$ oxidation, separated by TLC and quantitated. The distribution of label is based on a total of $125,000 \mathrm{dpm}$.

${ }^{b}$ Chemical oxidation of this alkan-2-ol gave rise to an unlabelled $\mathrm{C}_{15}$ methyl ketone with the ${ }^{3} \mathrm{H}$ label in the water phase.

3-oxopalmitoyl-CoA mentioned above is a small difference compared to that occurring when $\left(2{ }^{3} \mathrm{H}\right)$-pentadecan-2-ol is used as a precursor (Table VI). Of the total radioactivity $50-68 \%$ was in the $\mathrm{C}_{31}$ ester and minor amounts were detected in $\mathrm{C}_{27}$ and $\mathrm{C}_{29}$ esters from $c e r-u^{69}$ and $-c^{36}$. All the radioactivity in the total ester fraction in the experiments with the first four precursors listed in Table VI was exclusively present in the alkan-2-ol esters. In contrast to these results, the alkan-2-ol containing esters accounted for 57,52 and $0 \%$ of the labelled esters in $c e r-u^{69},-c^{36}$ and $-q^{42}$, respectively, when $(9,10-$ ${ }^{3} \mathrm{H}$ )-palmitoyl-CoA was used as the substrate. The corresponding figure for $\left(1-{ }^{14} \mathrm{C}\right)$-myristic acid and $c e r-u^{69}$ was $31 \%$. The labelled ester distribution resulting from $\left(9,10-{ }^{3} \mathrm{H}\right)$-palmitoylCoA feeding is interesting in that the amount of label in $C_{33}$ is less than in the $C_{31}$ and $C_{35}$. $\left(1-{ }^{14} \mathrm{C}\right.$ )-octadecan-1-ol was exclusively incorporated into the alkan-1-ol containing esters, and the data are therefore not included in Table VI.

The epicuticular wax esters from barley spikes are composed of three basic structural components: Alkan-1-ols and alkan-2-ols esterified to the third component, the fatty acid moiety. These were separated and quantitated giving the results presented in Table VII. Use of the first four substrates in Table VII resulted in exclusive labelling of the alkan-2-ol ester moieties. By contrast, radioactivity from $\left(1-{ }^{14} \mathrm{C}\right)$-octadecan1-ol was only detected in the alkan-1-ol ester moieties. These five substrates did not label the fatty acid moieties. The latter accounted for $78-94 \%$ of the label in the esters when $\left(9,10-{ }^{3} \mathrm{H}\right)$ palmitoyl-CoA and $\left(1-{ }^{14} \mathrm{C}\right)$-myristic acid were fed. This is in agreement with the results obtained previously using palmitic and myristic acids (76), and when $\left(1-{ }^{14} \mathrm{C}\right)$-myristic acid was used (Table VII). The corresponding figures for the alkan-2-ol with $\left(9,10-{ }^{3} \mathrm{H}\right)$-palmitoyl-CoA obtained in the present studies, however, are much lower than that reported using the ${ }^{3} \mathrm{H}$-labelled free fatty acid (76). This difference in the labelling pattern might be caused by the presence of differing contaminating amounts of ${ }^{3} \mathrm{H}$-labelled myristic acid in the $\left(9,10-{ }^{3} \mathrm{H}\right)$-palmitic acid preparation used (76), or differing extents of enzymatic degradation of the $C_{16}$ fatty acid substrates. The ${ }^{3} \mathrm{H}$-labelled palmitic acid derivatives used in the present studies have been analyzed by radio-GC and found to contain less than $0.1 \%{ }^{3} \mathrm{H}$-labelled myristic acid.

Further identification of the alkan-2-ol moieties was carried out using a combination of radio-TLC and -GC before or after $\mathrm{K}_{2} \mathrm{Cr}_{2} \mathrm{O}_{7}$ 
oxidation of the alcohols (section 2.6). The alkan-2-ols isolated from the experiments with (9,10- $\left.{ }^{3} \mathrm{H}\right)$-3-oxo-palmitoyl-CoA, $\left(2-^{14} \mathrm{C}\right)$-pentadecan-2-one and $\left(2-{ }^{3} \mathrm{H}\right)$-pentadecan-2-ol behaved in all cases identically to authentic pentadecan-2-ol. Similarly, that formed from (10,11'H)-heptadecan-2-one was identical to heptadecan-2-ol. Those resulting from $\left(9,10-{ }^{3} \mathrm{H}\right)$-palmitoyl-CoA and $\left(1-{ }^{4} \mathrm{C}\right)$-myristic acid feeding were likewise shown to be pentadecan-2-ol in agreement with the results obtained previously (76).

\subsection{Analyses for the presence of 3-0xoacyl- CoA thiolase, thioesterase and decarboxylase activities in the tissue slice system}

The presence of 3-oxoacyl-CoA thiolases and thioesterases are well documented in plant tissues $(1,7,11,15,27,29,30,31,33,47)$. The first type of enzyme cleaves the 3-oxo acid in the presence of $\mathrm{COA}$ to give acetyl-CoA and an acyl-CoA derivative two carbons shorter than the original substrate. A spectrophotometric assay for the 3-oxoacyl-CoA thiolase (46) using 3-oxopalmitoyl-CoA showed that it was not present at any measurable level in a crude extract of the tissue slices. Indirect evidence also infers that this enzyme does not play a role in the degradation of the 3-oxo acid. After incubation with ${ }^{3} \mathrm{H}$-labelled 3-oxopalmitoyl-CoA, neither free myristic acid nor its $\mathrm{CoA}$ derivative accumulated. Furthermore, the presence of the $C_{14}$ chain degradation product would inevitably give rise to label in the acyl moiety of the esters. This was not observed (Table VII). An assay was also carried out for the thioesterase which cleaves the thioester bond to yield free 3-oxo acid plus $\mathrm{CoA}$. When tissue slices were incubated with $\left(1-{ }^{14} \mathrm{C}\right)$-labelled palmitoyl-CoA or its 3-oxo derivative for only $10 \mathrm{~min}$. $60-70 \%$ of the label could be extracted with $\mathrm{CHCl}_{3}$ after acidification. Less than $0.1 \%$ of the label fed to boiled tissue could be recovered in this way. TLC analysis revealed the presence of free palmitic acid and $a{ }^{14} \mathrm{C}$-labelled compound tentatively designated by its $R_{f}$ value (8) as 3-oxopalmitic acid. Reduction of the latter with $\mathrm{NaBH}_{4}$ gave Dl-3-hydroxypalmitic acid confirming the identification. These results clearly demon- strated the presence of a very active thioesterase in the tissue slice system.

When a time course experiment for the thioesterase was conducted using a radio-TLC analysis, a remarkable difference between the 3-oxopalmitoyl-CoA and palmitoyl-CoA substrates became evident. Relatively high recovery of the fed labelled palmitoyl-CoA was possible after 1 and 2 hours, 45 and $40 \%$, respectively. The corresponding figures for $\left(1-{ }^{14} \mathrm{C}\right)$-3-oxopalmitoyl-CoA were 35 and $2 \%$. After 3 hours of incubation the 3-oxopalmitic acid peak was totally eliminated from the radio-TLC traces. That the 3-oxo acid was decarboxylated to form ${ }^{14} \mathrm{CO}_{2}$ is suspected by the following observations. A significant proportion of the radioactivity (approx. 10\%), disappeared when the $\mathrm{pH}$ of the incubation mixture was decreased to 0 with 10 $\mathrm{N}-\mathrm{H}_{2} \mathrm{SO}_{4}$. This strongly infers the presence of ${ }^{14} \mathrm{CO}_{2}$ in the reaction mixture. On the other hand, radio-TLC revealed that ${ }^{3} \mathrm{H}$-labelled methyl ketones accumulated when $\left(9,10-{ }^{3} \mathrm{H}\right)-3-$ oxopalmitoyl-CoA was used as the substrate. Decarboxylation of a 3-oxo acid can take place either spontaneously (67) or be mediated by an enzyme, a decarboxylase. Long chain 3-oxo acids are much more stable than the shorter homologues $(45,51)$. This stability was evident during the synthesis of the methyl ketones (section 2.4.1). That is, 3-oxopalmitic acid could be isolated if lower temperatures and shorter incubation times were employed. This is in agreement with the results of MITZ et al. (45) and NUGTEREN (51). Likewise, the 3-oxo acids i) present in milk triglycerides (34), ii) produced by a NADPH depleted yeast fatty acid synthetase $(65)$, iii) or synthesized by the chain elongating system from rat liver microsomes $(8,9,10)$ were only decarboxylated if heated (34) or treated with base $(8,9,10,65)$. A spontaneous non-enzymatic decarboxylation of the 3-oxo acid is therefore unlikely to take place in the present tissue slice system. The stability of the 3-oxoacyl-CoA substrates was also very good and no degradation was detected using standard conditions (section 2.6) when these substrates were incubated with boiled tissue for 2 hours. These investigations lead to the conclusion that a very active decarboxylase is present in the tissue slice system. 

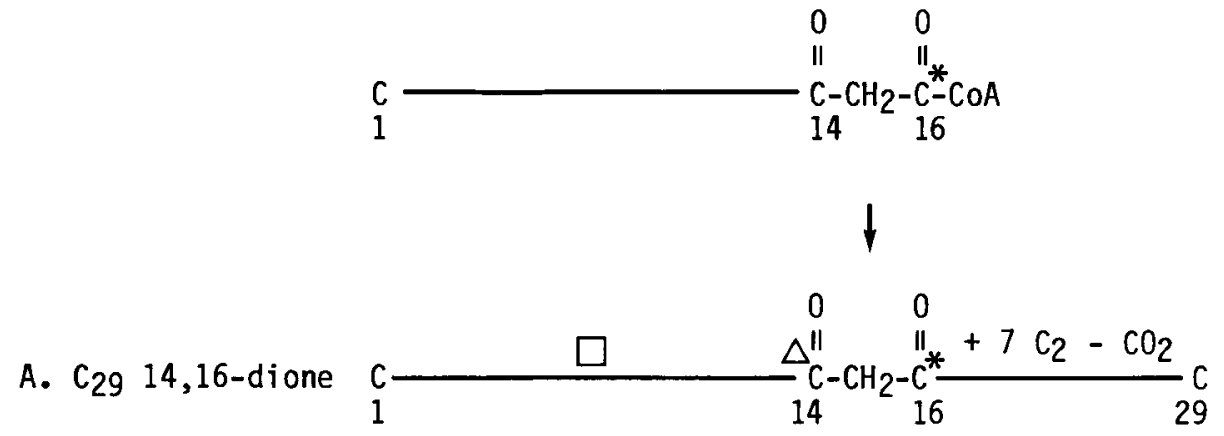

B. $C_{31} 14,16$-dione

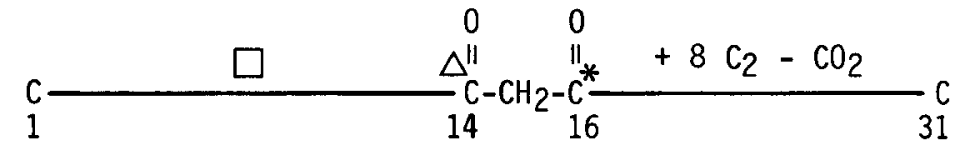

C. "

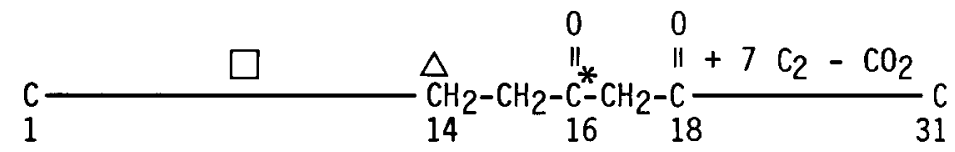

D. $C_{33} 16,18$-dione

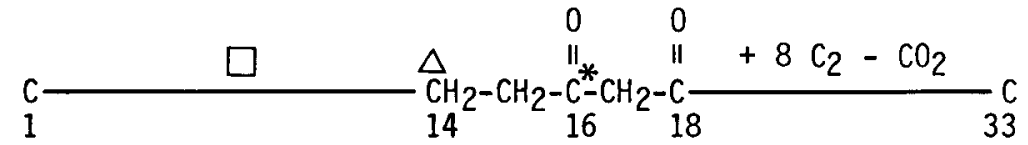

Figure 11. Possible modes of synthesis of three $\beta$-diketones via elongation from 3-oxopalmitoyl-CoA in barley. Schemes A, C and D occur during in vivo biosynthesis. Scheme B has been induced. The numbering system is in the direction of chain elongation. Thus for the 3-oxopalmitoyl-CoA precursor (upper structure) and in scheme $\mathrm{C}$ they are opposite to IUPAC nomenclature rules. $\mathrm{C}_{29}=$ nonacosan, $\mathrm{C}_{31}=$ hentriacontan and $\mathrm{C}_{33}=$ tritriacontan. Positions of label are shown in the $\beta$-diketone carbon chains after feeding $\left(1-{ }^{14} \mathrm{C}\right)-3$-oxopalmitoyl-CoA $={ }^{*}$, as well as $\left(9,10-{ }^{3} \mathrm{H}\right)$-3-oxopalmitoyl-CoA $=\square$ and $\left(1-{ }^{14} \mathrm{C}\right)$-myristic acid $=\Delta$.

\section{DISCUSSION}

Compositional analysis, radioactive tracer and inhibitor studies $(41,43,49,74,76)$ supported the hypothesis that hentriacontan-14,16dione (the predominant $\beta$-diketone in barley spike wax) is most likely formed by the $\beta$-ketoacyl elongase in the following manner: palmitic acid, the end product of de novo fatty acid synthesis is elongated with a $\mathrm{C}_{2}$ unit to form a $\mathrm{C}_{18}$ 3-oxoacyl intermediate. Protection of the $\beta$-diketo group and further elongation by $7 \mathrm{C}_{2}$ units leads to a $C_{32} \beta$-diketo acid. A final decarboxylation of the $C_{32} \beta$-diketo acid and release of the protection group gives the $\mathrm{C}_{31} \beta$-diketone molecule (Figure $11 \mathrm{C}$ ). Previous experiments (43) revealed that myristic acid can be directly used by the $\beta$-keto elongase to form $C_{29}$ and $\mathrm{C}_{31} \beta$-diketones (Figure $11 \mathrm{~A}$ and $\mathrm{B}$ ). In addition myristic acid could be elongated before action of the $\beta$-keto elongase to give rise to $C_{31}$ and $\mathrm{C}_{33} \beta$-diketones (Figure $11 \mathrm{C}$ and $\mathrm{D}$ ). In vivo, however, the pathway summarized in Figure 11 B is not operational. By analogy a similar result is expected when $\left(9,10-{ }^{3} \mathrm{H}\right)$-3-oxopalmitoyl$\mathrm{CoA}$ is used directly as a primer for the $\beta$-keto elongase to form $\mathrm{C}_{29}$ and $\mathrm{C}_{31} \beta$-diketones (Figure 
$11 \mathrm{~A}$ and B). Synthesis in this manner accounts for $59 \%$ of the radioactivity incorporated into the $\beta$-diketones (see Tables IV and V). The remaining $37 \%$ of the 3 -oxopalmitoyl-CoA is converted to palmitic acid and elongated to form the $\mathrm{C}_{18}$ 3-oxoacyl-CoA intermediate that in turn leads to the $C_{31}$ and $C_{33} \beta$-diketones as in Figure $11 \mathrm{C}$ and $\mathrm{D}$. The enzymatic reduction and dehydrase steps involved in the conversion of the 3-oxopalmitoyl-CoA to palmitic acid $\left(\mathrm{C}_{16}\right)$ can be carried out theoretically by a fatty acid synthetase, an acyl elongase or by a $\beta$-keto elongase. The latter two are enzyme complexes which carry out a similar series of enzymatic reactions to those of a fatty acid synthetase. An involvement of a fatty acid synthetase or acyl elongase, however, inevitably gives rise to the formation of $C_{16}$ and $C_{18}$ or longer chain fatty acids, which are known to be readily esterified with alcohols to give long chain esters. This was not observed with the specified 3-oxopalmitoylCoA substrate, and the most probable candidate, therefore, for converting this substrate into palmitic acid and retaining it only for the $\beta$-diketone synthesis is the $\beta$-keto elongase.

The potential $C_{31} \quad \beta$-diketone molecules formed by feeding $\left(1-{ }^{14} \mathrm{C}\right) 7-3-0 x 0-p a l m i t o y l-$ CoA yield by cleavage a $C_{16}$ acid moiety from both the $C_{16-3 \mid}$ end (Figure $11 \mathrm{~B}$ ) and the $C_{1-16}$ end (Figure $11 \mathrm{C}$ ). It is therefore not possible to determine whether this substrate is used directly as a primer for the $\beta$-keto elongase or whether it is converted first to palmitic acid before being used for synthesis of the $C_{31} \beta$-diketone molecule. The low amount of radioactivity (3\%) present in the $\mathrm{C}_{29} \beta$-diketone from $\left(1-{ }^{14} \mathrm{C}\right)$ 3-oxopalmitoyl-CoA does, however, indicate some direct use. Upon cleavage of these $\beta$-diketones, the only possible $C_{14}$ labelled fatty acid should come from the $\mathrm{C}_{29} \beta$-diketone (Figure $11 \mathrm{~A}$ ). Surprisingly, $19 \%$ more label than expected was found in the $C_{14}$ fatty acid moiety (see Tables IV and V). This result infers, that the $C_{31} \beta$-diketones contain label in the $C_{1-14}$ or $\mathrm{C}_{18-31}$ end of the molecules shown in Figure 11 $B$ and $C$, respectively.

In seeking an explanation for this unexpected labelling pattern, the action of other enzymes on the 3-oxoacyl-CoA precursors have to be considered. The results in section 3.6 provide
DE NOVO SYNTHESIS

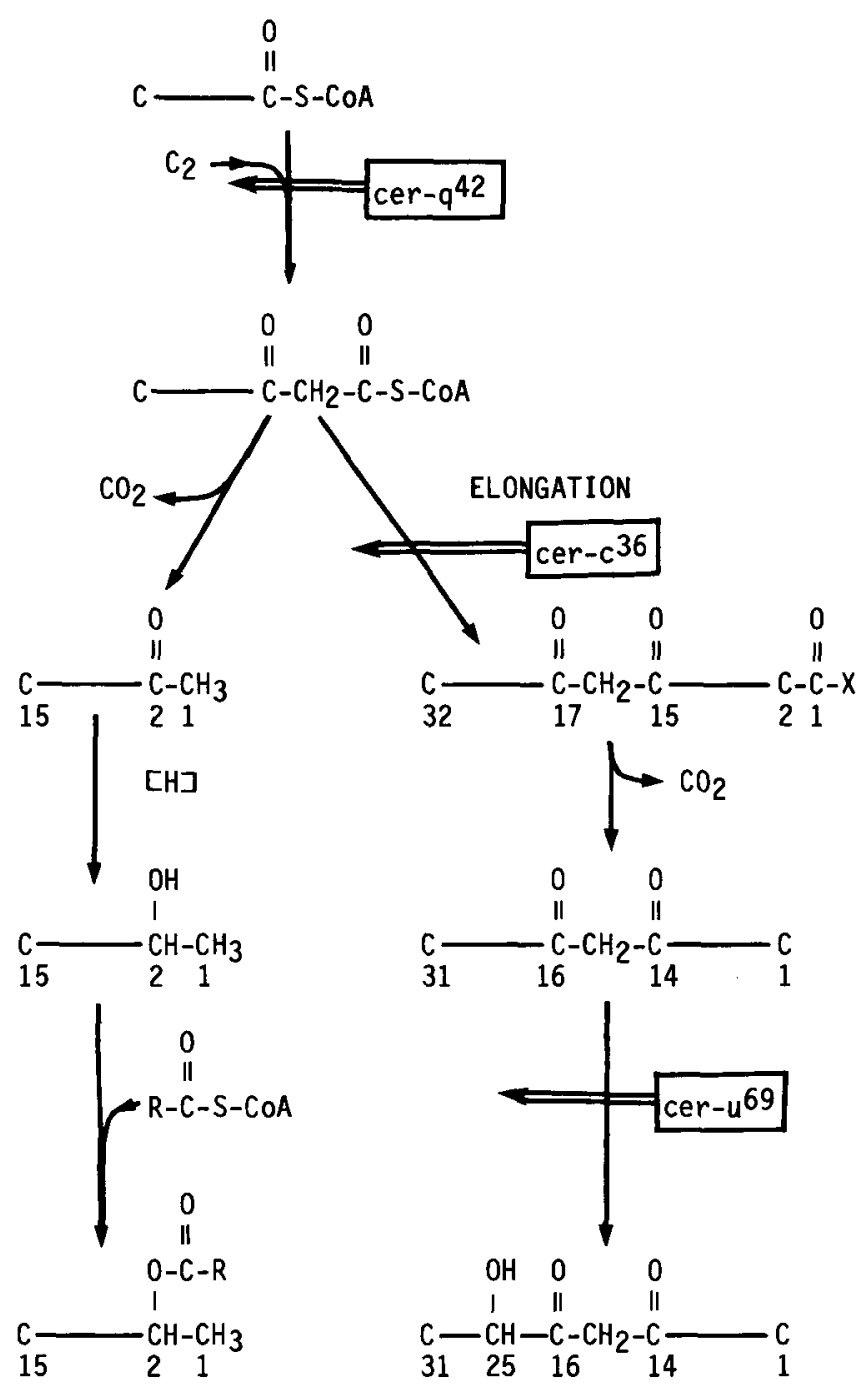

Figure 12. Reaction sequences involved in the biosynthesis of the 3-oxoacyl derived epicuticular lipids. The key 3-oxoacyl intermediate is produced via action of the $\beta$-ketoacyl condensing enzyme on a fatty acyl-CoA intermediate in de novo synthesis. The pathway on the left illustrates the conversion of the 3-oxoacyl-CoA intermediate exemplified by $\mathrm{C}_{15}$ into methyl ketones, then alkan-2-ols and finally esterification of the latter to give the alkan-2-ol containing esters. On the right the key intermediate is elongated and decarboxylated to give the $\beta$-diketones exemplified by hentriacontan14,16-dione, which may then be converted to hydroxy$\beta$-diketones. Only the alkan-2-ol containing esters, $\beta$-diketones and hydroxy- $\beta$-diketones are found in barley epicuticular wax. 
strong evidence for both an active thioesterase and decarboxylase in the tissue slice preparations. Extensive studies using various plant systems have shown that ${ }^{14} \mathrm{CO}_{2}$ can be used as an effective precursor for fatty acid synthesis (22, $58,61,64)$. Combining these observations leads to the suggestion that some of the ${ }^{10} \mathrm{CO}_{2}$ released from $\left(1-{ }^{14} \mathrm{C}\right)-3$-oxopalmitoyl-CoA by the action of the decarboxylase is converted to acetyl-CoA or malony!-CoA and re-channelled not only into the $\beta$-diketones and alkan-2-ol moieties of the esters (see Table III), but also into the hydrocarbons, aldehydes, primary alcohols and free fatty acids. The present results support the earlier contention (43) that the $\beta$-keto elongase has a very stringent primer specificity. Earlier work revealed that only $C_{14}, C_{15}$ or $C_{16}$ fatty acids are readily accepted for $\beta$-diketone synthesis. $A$ low level of synthesis, however, can take place from $\mathrm{a} \mathrm{C}_{12}$ fatty acid to form the novel $C_{27} \beta$-diketone (heptacosan-12,14-dione). Among the derivatives of the specified fatty acids studied herein, the 3-oxoacyl-CoA substrates were found to be the best primers. To further delimit the specificity of the $\beta$-ketoacyl elongase a primer having the dicarbonyl group localized even closer to the $C_{1}$ end of the molecule, namely $\left(1-{ }^{14} \mathrm{C}\right)$ 10,12-dioxoeicosanoic acid, was synthesized and incubated with the tissue slices from cer- $u^{69}$. In the direction of synthesis of the $\beta$-diketone carbon chain this precursor has the $\beta$-dicarbonyl group in position 9,11 when counting from the $\mathrm{CH}_{3}$ end of the molecule (Figure 9, II). An elongation with 2 or $3 \mathrm{C}_{2}$ units (to give a total of 6.5 or $7.5 C_{2}$ units beyond the $\beta$-dicarbonyl group) should give rise to $C_{23}$ or $C_{25} \beta$-diketone (triacosan- or pentacosan-9,11-dione). No label was, however, observed in the $\beta$-diketones. This result demonstrates that moving the $\beta$-dicarbonyl groups as far as three carbons closer to the $C_{1}$ end $(14,16$ to 9,11$)$ could make the substrate unusable by the $\beta$-ketoacyl elongase. Most likely the four $C_{2}$ units already present beyond the $\beta$-dicarbonyl group are the primary cause for this substrate not serving as a primer for the $\beta$-ketoacyl elongase. Interestingly, as no label was present in the other wax classes, the acyl elongases are also unable to use $\left(1-{ }^{14} \mathrm{C}\right)-10,12$ dioxoeicosanoic acid as a wax precursor, although eicosanoic acid may be readily elongated by them $(14,33)$.

A 3-oxoacyl-CoA derivative acts as a common precursor for the biosynthesis of both the alkan2 -ol esters and the $\beta$-diketones as shown in Figure 12. The two alternative branches of the pathway presumably compete for a common intermediate. In vivo, the $\beta$-diketones and alkan-2-ol esters amount to 50 and $4.7 \%$ by weight of cer-u $u^{69}$ spike wax, respectively (72). Feeding $(9,10-\mathrm{H})$-3-oxopalmitoyl-CoA by contrast gave five times more label in the alkan-2-ol esters than in the $\beta$-diketones. In the in vitro conditions the first of the three enzymes involved in the alkan-2-ol ester synthesis (Figure 12) must be more active than the first enzyme of the pathway yielding $\beta$-diketones. The presence of an active decarboxylase is supported by the accumulation of ${ }^{3} \mathrm{H}$-labelled methyl ketone when $\left(9,10-{ }^{3} \mathrm{H}\right)$-3-oxopalmitoyl-CoA was fed to tissue slices. Whereas both pathways were shown to use the $\mathrm{C}_{16}$ and $\mathrm{C}_{18}$ 3-oxoacyl intermediates, the shorter chain, $\mathrm{C}_{12}$ and $\mathrm{C}_{14}$ molecules are able in vivo to enter the alkan-2-ol ester branch to form the $C_{11}, C_{13}, C_{15}$ and $C_{17}$ alkan-2-ol esters present in barley spike epicuticular wax (44.77). The second step in the alkan-2-ol ester pathway is a reduction of the methyl ketone to give rise to the alkan-2-ol (Figure 12). The high rate by which exogenous methyl ketones were incorporated into the alkan-2-ol esters clearly demonstrated the presence of a methyl ketone reductase. The alternative reaction sequence. involving a reduction of the 3-oxoacyl-CoA precursor to form a 3-hydroxyacyl derivative followed by a decarboxylation. is ruled out by the observation that L-3-hydroxypalmitoyl-CoA and the various DL-3-hydroxy fatty acids tested labelled the alkan-2-ol esters very poorly. The third and final enzymatic reaction in this branch pathway is esterification of the alkan-2-ols to form the final lipid (Figure 12). The presence of an ester synthetase in the tissue slices capable of using alkan-2-ols as substrates was inferred from the feeding studies using $\left(2-{ }^{3} \mathrm{H}\right)$-pentadecan-2-ol.

The identification of the ester alcohol moieties (section 3.5) plus the determination of the chain lengths distributions of the esters (Table VI) allows a calculation to be made of the chain lengths of the acid moieties of the esters. The 
alkan-2-ols synthesized from the 3-oxopalmitoyl-CoA and the two methyl ketone precursors must be esterified primarily with $\mathrm{C}_{18}$ and $\mathrm{C}_{20}$ fatty acids. In contrast when either alkan-2-ols or alkan-1-ols were fed to the tissue slices they were esterified predominantly to a $\mathrm{C}_{16}$ fatty acid. This difference strongly suggests the presence of two ester synthetases in the tissue slices. Furthermore, since access to the $\mathrm{C}_{18}$ and $\mathrm{C}_{20}$ fatty acids occurs only when 3-oxopalmitoyl-CoA but not the alkan-2-ol is fed, the deduction can be drawn that the intermediates in this pathway remain in effect bound to an enzyme complex consisting of at least the decarboxylase, reductase and ester synthetase (Figure 12). Another ester synthetase specific for the alkan-1-ols must be present not only in the spikes but also in the leaves (74). In barley leaves the biosynthetic pathways shown in Figure 12 do not function (74). A crude microsomal preparation from the primary leaf of barley catalyzes the esterification of alkan-1-ols, primarily with palmitic acid (4). The chain length specificity of the alcohol moiety of this enzyme system is very broad (4). Its characteristics suggest that it may be similar if not identical to the alkan-2-ol ester synthetase activity in the presently investigated tissue slices. Whether the latter ester synthetase can accept a $C_{15}$ alkan-2-ol to form a $C_{31}$ alkan-2-ol ester remains to be investigated.

A few studies have described a reduction analogous to that taking place in the alkan-2-ol ester pathway. For example exogenous methyl ketones are converted to the corresponding alkan-2-ols in HeLa cells (48), and 3-hydroxyoctadecan-2-one (acyloin) is reduced to form octadecan-1,3-diol (alkan-1,3-diol) in the microsomes from the uropygial gland of the ring necked pheasant $(12,32,57)$. Such reductions may be carried out by an acyl-CoA or alternatively by an aldehyde reductase having a broad substrate specificity (12).

The most likely sites of action of the mutations $c e r-u^{69},-c^{36}$ and $-q^{42}$ are indicated in Figure 12. The very marked block in the synthesis of hydroxy- $\beta$-diketones and the compensatory increase in the amount of the $\beta$-diketones $c e r-u^{69}$ wax clearly pinpoints where this mutation cer$u^{69}$ acts (74). Previous compositional analyses and tracer studies revealed only the approx. sites of action of $c e r-c^{36}$ and $-q^{42}$ due to lack of information about these biosynthetic pathways (75). Thus cer- $q^{42}$ was inferred to act so that a given intermediate in fatty acid synthesis, most likely the myristic or palmitic acids, could not enter either branch pathway shown in Figure 12. The mutation cer- $c^{36}$ expresses itself beyond the branch point and totally inhibits the $\beta$-diketone pathway. Since in the present studies free acids plus $\mathrm{CoA}$ derivatives were not incorporated into the products of these two pathways while 3-oxoacyl-CoA's were effective precursors of the esterified alkan-2-ols, the defect in $c e r-q^{42}$ can now be pinpointed to a condensing enzyme, the only enzyme known to act between the tested substrates in fatty acid synthesis. The results of the present experiments are in accord with the proposed site of action of $c e r-c^{36}$, but do not delimit it more exactly.

No mutation in the cer-cqu gene affecting either the decarboxylase, reductase or ester synthetase of the alkan-2-ol ester pathway have been found. Mutants defective in only one of these three enzymatic steps are unlikely to be found because the alkan-2-ol esters, in contrast to the $\beta$-diketone wax classes, do not contribute much if at all to the plant phenotype. The three mutations specified above belong to the single gene, cer-cqu, which determines a multifunctional polypeptide (75). Whether or not any of the three enzymatic steps in the alkan-2-ol ester pathway are part of the same multifunctional polypeptide is unknown. The most direct approach to determine this will be the successful isolation and characterization of the enzymes themselves.

\section{ACKNOWLEDGEMENTS}

I am indebted to Dr. P. VON WETTSTEINKNOWLES for constructive suggestions and for reviewing the manuscript, to Drs. D. BISHOP and $A$. FOGERTY for helpful assistance in preparing the $C_{20} \beta$-diketo fatty acid, to Dr. J.Ø. MADSEN for taking the mass spectra, to Dr. A.G. NETTING and P.B. HøJ for stimulating discussions, to M. PETERSEN for outstanding technical assistance, to N. RASMUSSEN for preparing the figures, to B. PETERSEN for growing the plants, to L. SEJERSEN and S. HorsgaARD for modi- 
fication of the computer programm for the radio-GC and to $B$. HANSEN for maintenance of the radio-GC.

\section{REFERENCES}

1. ANDREws, J. \& K. KeEgStra: Acyl-CoA synthetase is localized in the outer membrane and acylCoA thioesterase in the inner membrane of pea chloroplast envelopes. Plant Physiol. 72, 735-740 (1983)

2. APPELQVIST, L-A: A simple and convenient procedure for the hydrogenation of lipids on the microand nanomole scale. J. Lipid Res. 13, 146-148 (1972)

3. Avato, P., J.D. Mikkelsen \& P. von WettsteinKNOWLES: Synthesis of epicuticular primary alcohols and intracellular fatty acids by tissue slices from $c^{2}-j^{-59}$ barley leaves. Carlsberg Res. Commun. 47, 377-390 (1982)

4. Avato. P.: Synthesis of wax esters by a cell-free system from barley leaves. (Submitted to Planta, Berlin)

5. BaumanN, W.J. \& H.K. Mangold: Quantitative reactions for the chain elongation of aliphatic compounds. J. Lipid Res. 9, 287 (1968)

6. BaumanN, W.J. \& H.K. MANGold: Reactions of aliphatic methanesulfonates. I. Syntheses of longchain glyceryl-(1) ethers. J. Org. Chem. 29, 30553057 (1964)

7. BEEVERS, H: The role of the glyoxylate cycle. In: The Biochemistry of Plants. A Comprehensive Treatise. Lipids: Structure and Function. P.K. Stumpf ed., Academic Press, New York, 5, 117 130 (1980)

8. BERNERT JR. J.T. \& H. SPRECHER: An analysis of partial reactions in the overall chain elongation of saturated and unsaturated fatty acids by rat liver microsomes. J. Biol. Chem. 252, 6736-6744 (1977)

9. BERNERT JR. J.T. \& H. SPRECHER: The effect of bovine serum albumin on partial reactions of palmitoyl-CoA chain elongation by rat liver microsomes. Biochim. Biophys. Acta 531, 44-55 (1978)

10. Bernert JR. J.T. \& H. SPRECher: The isolation of acyl-CoA derivatives as products of partial reactions in the microsomal chain elongation of fatty acids. Biochim. Biophys. Acta 573, 436-442 (1979)

11. Block, M.A., A.-J. DORNE, J.JOYARD \& R. DOUCE: The acyl-CoA thioesterases are located on the outer and inner membrane of the chloroplast envelope, respectively. Febs Letters 153, 377-381 (1983)
12. BuCKNer, J.S. \& P.E. Kolattukudy: Biochemistry of bird waxes. In: Chemistry and Biochemistry of Natural Waxes. P.E. Kolattukudy ed., Elsevier Scientific Publishing Co., Amsterdam. pp. 147200 (1976)

13. Carroll, K.K.: Separation of lipid classes by chromatography on florisil. J. Lipid Res. 2, 135 141 (1961)

14. Cassagne, C. \& R. Lessire: Biosynthesis of saturated very long chain fatty acids by purified membrane fractions from leek epidermal cells. Arch. Biochem. Biophys. 191, 146-152 (1978)

15. CoOper, T.G. \& H. BeEvers: $\beta$-oxidation in glyoxysomes from castor bean endosperm. J. Biol. Chem. 244, 3514-3520 (1969)

16. EgGerer, H \& F. LYNEN: Zur Biosynthese der Fettsäuren. Synthese und Eigenschaften von Smalonyl-CoA. Biochem. Z. 335, 540-547 (1962)

17. Eglinton, G., D.H. HunNeman \& K. DouraGHiZADEH: Gas chromatographic-mass spectrometric studies of long chain hydroxy acids. II: The hydroxy acids and fatty acids of a 5000-year-old lacustrine sediment. Tetrahedron 24, 5929-5941 (1968)

18. Ellmann, G.L.: Tissue sulfhydryl groups. Arch. Biochem. Biophys. 82, $70-77$ (1959)

19. Fogerty, A.C., A.R. Johnson, J.A. Pearson \& F.S. Shenstone: Preparation of methyl malvate from Sterculia foetida seed oil. J. Am. Org. Chem. Soc. 42, 885-887 (1965)

20. Fogerty, A.C., A.R. Johnson \& J.A. Pearson: Ring position in cyclopropene fatty acids and stearic acid desaturation in hen liver. Lipids 7, 335-338 (1972)

21. Gensler, W.J., K.W. Pober, D.M. Solomon \& M.B. FLOYD: Syntheses of methyl malvalate and methyl 5,6-methano-5-undecenoate. J. Org. Chem. 35, $2301-2307$ (1970)

22. HARwood, J.L.: The synthesis of acyl lipids in plant tissues. Prog. Lipid Res. 18, 55-86 (1979)

23. HenRy, L.E.A., J.D. MikKELSEN \& B.L. MøLler: Pigment and acyl lipid composition of photosystem I and II vesicles and of photosynthetic mutants in barley. Carlsberg Res. Commun. 48, 131-148 (1983)

24. HOOPER, N.K. \& J.H. LAw: Mass spectrometry of derivatives of cyclopropene fatty acids. J. Lipid Res. 9, 270-275 (1968)

25. HORN, D.H.S., Z.H. KRANZ \& J.A. LAMBERTON: The composition of Eucalyptus and some other leaf waxes. Aust. J. Chem. 17, 464-476 (1964)

26. Horning, M.G., A.M. Moss \& E.C. Horning: Fraction and gas-liquid chromatographic behavior of isometric steroid ketone methoxime derivatives. Anal. Biochem. 22, 284-294 (1968) 
27. JOYARD, J. \& P.K. STUMPF: Characterization of an acyl-Coenzyme $A$ thioesterase associated with the envelope of spinach chloroplasts. Plant Physiol. 65, 1039-1043 (1980)

28. KaWAMURA, K. \& R. IshiwataRI: Tightly bound $\beta$-hydroxy acids in a recent sediment. Nature 297, 144-145 (1982)

29. KolatTUKUDY, P.E.: Mechanisms of synthesis of waxy esters in broccoli (Brassica oleracea). Bichem. 6, 2705-2717 (1967)

30. Kolattukudy, P.E.: Biosynthesis of cuticular lipids. Ann. Rev. Plant Physiol. 21, 163-192 (1970)

31. Kolattukudy, P.E., R. Croteau \& J.S. BUCKNER: Biochemistry of plant waxes. In: Chemistry and Biochemistry of Natural Waxes. P.E. Kolattukudy, ed., Elsevier, Amsterdam, pp. 289347 (1976)

32. KolatTuKudy, P.E., R.G. RILEY \& L. ROGERS: Biosynthesis of alkane-2,3-diols: Enzymatic reduction of 3-hydroxyoctadecane-2-one to octadecane-2,3-diol by a NADPH (B-side) specific microsomal reductase from the uropygial glands of ringnecked pheasants (Phasianus colchicus). Arch. Biochem. Biophys. 189, 433-440 (1978)

33. KolatTukudy, P.E.: Cutin, suberin, and waxes. In: The Biochemistry of Plants. A comprehensive Treatise. Lipids: Structure and Function, P.K. Stumpf ed., Academic Press, New York, 5, 571645 (1980)

34. LAWRENCE, R.C.\&J.C. HAWKE: The incorporation of $\left(1-{ }^{14} \mathrm{C}\right)$-acetate into the methyl ketones that occur in steam-distillates of bovine milk fat. Biochem. J. 98, 25-29 (1966)

35. LUDWIG, S.A.\& H.SPRECHER: Substrate specificity studies on the malonyl-CoA dependent chain elongation of all-cis polyunsaturated fatty acids by rat liver microsomes. Arch. Biochem. Biophys. 197, 333-341 (1979)

36. LUNDQVIST, U. \& D. vON WETTSTEIN: Induction of eceriferum mutants in barley by ionizing radiations and chemical mutagens. Hereditas $48,342-$ 362 (1962)

37. LUNDQViST, U., P. VON WETTSTEIN-KNOWLES \& D. vON WETTSTEIN: Induction of eceriferum mutants in barley by ionizing radiations and chemical mutagens. Hereditas 59, 473-504 (1968)

38. LUNDQVIST, U. \& P. VON WETTSTEIN-KNOWLES: Dominant mutations at cer-yy change barley spike wax into leaf blade wax. Carlsberg Res. Commun. 47, $29-43$ (1982)

39. LUNDQVist, U. \& P. VON WeTTSTEIN-KNOWLES: Phenotypic diversity of barley spike waxes resulting from mutations at cer- $n$. Carlsberg Res. Commun. 48, 321-344 (1983)

40. MCCLOSKEY,J.A:: Mass spectrometry of lipids and steroids. Methods Enz. XIV, 382-450 (1969)

41. Mikkelsen, J.D. \& P. von Wettstein-Knowles: Biosynthesis of $\beta$-diketones and hydrocarbons in barley spike epicuticular wax. Arch. Biochem. Biophys. 188, 172-181 (1978)

42. MikKelSEN, J.D.: The effects of inhibitors on the biosynthesis of the long chain lipids with even carbon numbers in barley spike epicuticular wax. Carlsberg Res. Commun. 43, 15-35 (1978)

43. MikKelsEN, J.D.: Structure and biosynthesis of $\beta$-diketones in barley spike epicuticular wax. Carlsberg Res. Commun. 44, 133-147 (1979)

44. MikKelsen, J.D. \& P. VON WeTtSTEIN-KNOWLES: Biosynthesis of esterified alkan-2-ols. Abstracts to 23rd International Conference on the Biochemistry of Lipids. Nyborg, Denmark (1981)

45. Mitz, M.A.. A.E. Axelrod \& K. HofmanN: The synthesis of higher aliphatic $\beta$-keto acids. J. Am. Chem. Soc. 72, 1231-1232 (1950)

46. Miyazawa, S., T. Osumi \& T. Hashimoto: The presence of a new 3-oxoacyl-CoA thiolase in rat liver peroxisomes. Eur. J. Biochem. 103, 589-596 (1980)

47. Murphy, D.J., K.D. MukherJee \& E. LATZKo: Lipid metabolism in microsomal fraction from photosynthetic tissue. Biochem. J. 213, 249-252 (1983)

48. NaCCARATO, W.F. \& J.R. GILBERTSON: Effect of pentadecan-2-one on lipid metabolism in HeLa cells. Lipids 5, 344-351 (1978)

49. NetTing, A.G. \& P. von WeTtSTEIN-KNOWles: Biosynthesis of the $\beta$-diketones of barley spike epicuticular wax. Arch. Biochem. Biophys. 174, 613-621 (1976)

50. NetTing, A.G. \& C. BARR: Design for an accurate and versatile radio gas chromatograph. Anal. Biochem. 84, 136-146 (1978)

51. Nugteren, D.H.: The enzyme chain elongation of fatty acids by rat-liver microsomes. Biochim. Biophys. Acta 106, 280-290 (1965)

52. Oikawa, Y., K. Sugano \& O. Yonemitsu: Meldrum's acid in organic synthesis. 2. A general and versatile synthesis of $\beta$-keto esters. J. Org. Chem. 43, 2087-2088 (1978)

53. Osumi, T. \& T. Hashimoto: Acyl-CoA oxidase of rat liver: A new enzyme for fatty acid oxidase. Biochem. Biophys. Res. Commun. 83, 479-485 (1978)

54. Osumi, T. \& T. Hashimoto: Occurence of two 3-hydroxyacyl-CoA dehydrogenases in rat liver. Biochem. Biophys. Acta 574, 258-267 (1979)

55. Osumi, $T$. \& T. Hashimoto: Purification and properties of mitochondrial and peroxisomal 3-hydroxyacyl-CoA dehydrogenases from rat liver. Arch. Biochem. Biophys. 203, 372-383 (1980) 
56. RAJU. P.K \& R. REISER: Gas-liquid chromatographic analysis of cyclopropene fatty acids. Lipids 1, 10-15 (1966)

57. Riley. R.G. \& P.E. Kolattukudy: Biosynthesis of alkane-2,3-diols: Chemical synthesis of 3-hydroxy- $\left(3-{ }^{14} \mathrm{C}\right)$-octadecan-2-one and its reduction to $\left(3{ }^{14} \mathrm{C}\right.$-octadecan-2,3-diol in the uropygial glands of ring-necked pheasants (Phasianus colchicus). Arch. Biochem. Biophys. 171, 276-281 (1975)

58. Roughan, P.G. \& C.R. Slack: Cellular organization of glycerolipid metabolism. Ann. Rev. Plant Physiol. 33, 97-132 (1982)

59. Sanchez, M., D.G. NiCholls \& D.N. Brindley: The relationship between palmitoyl-Coenzyme A synthetase activity and esterification of $s n$-glycerol 3-phosphate in rat liver mitochondria. Biochem. J. 132, 697-706 (1973)

60. Seubert, W., I. Lamberts, R. Kramer \& B. Ohly: On the mechanism of malonyl-CoA-independent fatty acid synthesis. $I$. The mechanism of elongation of long-chain fatty acids by acetyl-CoA. Biochim. Biophys. Acta 164, 498-517 (1968)

61. Sierberts, H.P. \& E. Heinz: Labelling experiments on the origin of hexa- and octadecatrienoic acids in galactolipids from leaves. Z. Naturforsch. 32 c, 193-205 (1977)

62. Steinman, H. \& R.L. Hill: Bovin liver crotonase (enoyl coenzyme A hydratase). EC 4.2.2.17 L-3hydroxyacyl-CoA hydrolyase. Methods Enz. 35, 136-151 (1975)

63. Stoffel, W. \& H.D. Pruss: Synthesis of eicosa-2trans-8,11,14-all cis-tetraenoic acid- $3-{ }^{14} \mathrm{C}$ and DL3-hydroxyeicosa-8,11,14-all cis-trienoic acid-3${ }^{14} \mathrm{C}$. J. Lipid Res. 8, 196-201 (1967)

64. STumpF. P.K.: Biosynthesis of saturated and unsaturated fatty acids. In: The Biochemistry of Plants. A comprehensive Treatise. Lipids: Structure and Function. P.K. Stumpf, ed., Academic Press, New York. 5, 177-204 (1980)

65. Sumper, M., D. Oesterhelt, C. Riepertinger \& F. LYNEN: Die Synthese verschiedener Carbonsauren durch den Multienzymkomplex der Fettsauresynthese aus Hefe und die Erklärung ihrer Bildung. Eur. J. Biochem. 10, 377-387 (1969)

66. TRKA.A.\& M.STREIBL: Mass spectra of long-chain aliphatic $\beta$-diketones and some of their derivatives. Collect. Czech. Chem. Commun. 39, 468-474 (1974)

67. VeIBEL, S.: The identification of organic compounds. A manual of qualitative and quantitative methods. G.E.C. Gad, Copenhagen (1971)
68. WALDI, D. von: Sprühreagentien für die Dünnschicht-chromatographie. In: Dünnschicht Chromatographie, E. Stahl, ed., Springer-Verlag, Berlin pp. 496-515 (1962)

69. WettStein-KNowles, P. von: The molecular phenotypes of the eceriferum mutants. In: Barley Genetics. 11. Proc. 2nd Intern. Barley Genet. Symp. (1969), R.A. Nilan ed., Washington State Univ. Press, Pullman, Wash., USA, pp. 146-193 (1971)

70. WetTStein-KNowles, P. von: Genetic control of $\beta$-diketone and hydroxy- $\beta$-diketone synthesis in epicuticular waxes of barley. Planta (Berl.) 106, 113-130 (1972)

71. WETTSTEIN-KNOWLES, P. vON: Esterified alkan-1ols and alkan-2-ols in barley epicuticular wax. Lipids 11, 478-484 (1976)

72. Wettstein-Knowles, P. von \& A.G. Netting: Composition of epicuticular waxes on barley spikes. Carlsberg Res. Commun. 41, 225-235 (1976)

73. WetTSTEIn-KNOWLES, P. von: Biosynthetic relationship between $\beta$-diketones and esterified alkan2-ols deduced from epicuticular wax of barley mutants. Molec. gen. Genet. 144, $43-48$ (1976)

74. Wettstein-Knowles, P. von: Genetics and biosynthesis of plant epicuticular waxes. In: Advances in the Biochemistry and Physiology of Plant Lipids. L-A. Appelqvist \& C. Liljenberg, eds. Elsevier/North Holland Biomedical Press. Amsterdam. pp. 1-26 (1979)

75. Wettstein-KNowles, P. von \& B. SøgaARd: The cer-cqu region in barley: gene cluster or multifunctional gene. Carlsberg Res. Commun. 45, 125-141 (1980)

76. WettSTEIN-KNOWLES, P. vON: Biosynthesis of epicuticular lipids as analyzed with the aid of gene mutations in barley. In: Biochemistry and Metabolism of Plant Lipids. J.F.G.M. Wintermans \& P.J.C. Kuiper, eds., Elsevier/North Holland Biomedical Press. Amsterdam. pp. $69-78$ (1982)

77. WETtSTEIN-KNOWLES. P. voN: Elongases and epicuticular wax biosynthesis. Physiol. Veg. 20, 797 809 (1982)

78. WoERLEE, E.F.G. \& J.C. MOL: A real-time gas chromatographic data system for laboratory applications. J. Chrom. Sci. 18, 258-266 (1980) 